\title{
TRADE CREDIT OR VERTICAL MERGER STRATEGY FOR FINANCIAL CONSTRAINED RETAILER IN A SUPPLY CHAIN WITH ASYMMETRIC COMPETING RETAILERS
}

\author{
Jizhou Zhan ${ }^{1}$, Tiantian Xu ${ }^{1, *}$, Xun Xu² and YaQi Jin ${ }^{1}$
}

\begin{abstract}
Motivated by the practices that many small and middle-sized enterprises (SME) retailers have financial constraints due to their limited budget and financing access, this paper studies the manufacturer's financial strategy (i.e., trade credit versus vertical merger with a capital-constrained retailer) in a supply chain with two financial asymmetric retailers. We first compare the equilibrium profits under different financing modes and find that if manufacturer's capital cost under trade credit or administrative cost under vertical merger is below a certain threshold, the manufacturer should finance instead of deselect the capital-constrained retailer even though the competition is intensified. Furthermore, manufacturer can choose a financing strategy based on the tradeoff between financing value and cost from trade credit or vertical merger. Under trade credit, the increased horizontal competition intensity is against the capital-constrained retailer while with vertical merger the competition intensity is harmful to the capital-abundant retailer. In addition, through investigating the impact of different financial modes on the equilibrium profits of the supply chain players, we find that whether trade credit can outperform vertical merger for both the manufacturer and the capital-constrained retailer depends on horizontal competition intensity, profit-sharing proportion and administrative cost of vertical merger. Moreover, the capital-abundant retailer will get the lowest profit when other participators act like an alliance. Our study provides a roadmap for the manufacturer to make a financing policy for capital-constrained retailer who competes with a funded retailer.
\end{abstract}

Mathematics Subject Classification. 90B06.

Received September 27, 2020. Accepted April 30, 2021.

\section{INTRODUCTION}

In order to increase the market share of product, manufacturers usually sell their products through multiple retailers and/or use multiple distribution channels to reach more consumers. For example, Haier - a brand household electrical appliance enterprise of China, has more than 30 thousands physical stores all over the country [23]. The increased number of channels and retailers can improve the recognition of the product, which also reduces manufacturers' bankruptcy risk [25]. However, there exists fierce competition among different

Keywords. Supply chain, financing strategy, Trade credit, vertical merger, Cournot competition.

1 School of Business, Nanjing Audit University, Nanjing 211815, PR China

2 Department of Management, Operations, and Marketing, College of Business Administration, California State University, Stanislaus, Turlock, CA 95382, USA

*Corresponding author: xutiantian1988@hotmail.com

(C) The authors. Published by EDP Sciences, ROADEF, SMAI 2021 
channels and retailers. The advantage of selling to multiple retailers can be offset by the increased competition. In the practice, one of the challenges that manufacturer, such as Haier, meets is many of retailers (e.g., franchised stores) are small and middle-sized enterprises (SMEs) [26]). SME retailers often have limited budget and are hard to access the external financing such as loans from the banks [9]. Under this circumstance, the manufacturer can just deselect the capital-constrained retailer to narrow the distribution channel or provide the financial assistant to the SMEs, who are in the competing sales market. Thus, when facing asymmetric financial retailers, it is necessary to study the impact of financial status of the supply chain players on the distribution strategy.

When choosing to sell product through capital-constrained retailer, the upstream manufacturer should concern the financial situations of downstream retailers, as limited fund may impede retailers to make an optimal order quantity, and thus prevent enlarging the product sales market. An effective way for manufacturers to release the retailers' financial constraints is to perform a strategic alliance with the SME retailers through merger and acquisition activities, especially vertical merger, which refers to upstream manufacturer merges with the downstream retailers through financial transactions [17,51]. For example, Haier initiated a "direct-sales" plan in 2006, and increased the investment of advertisement for its direct sales stores. If customers purchase Haier's product in a direct sales store, Haier will provide packages of services to customers, including B2C distribution with the fastest speed, complete product development, and post sales service. In this plan, Haier integrates the downstream retailer as a direct sales store, and controls the distribution channel for the market sales price and service of product. At the end of selling season, Haier shares the profits with the direct sales stores [54]. Vertical merger is commonly adopted in actual transactions. Like Luxottica, the largest producer of glasses in Italy, acquired $36 \%$ stock of Salmoiraghi \& Viganò, which is a Italian family glasses franchiser in 2012, and acquired the remaining shares of Salmoiraghi \& Viganò in 2016 [28]. In January of 2017, Coty, the largest perfume manufacturer in the world, spent $\$ 600$ million to acquire $60 \%$ shares of Younique, which is an online cosmetics retailer by its unique direct sales mode through E-business [44]. However, the vertical merger is not always favorable to the manufacturer. For example, Shanshan suit, which is a fashion manufacturer for men's clothing in China, announced the dissolution of direct sales stores in 2001 because Shanshan's capital and corporate management cannot catch up with the development of an extended sales retail network [6]. In this paper, we study the impact of competition on the vertical merger strategy in the supply chain with one manufacturer and two financial asymmetric retailers.

Besides vertical merger, trade credit is also an available approach to release retailer's financial constraint. Trade credit, which refers to a delay payment that manufacturers permit to retailers, is widely used in the practice, about $80 \%$ of firms in US market provide their products on trade credit [41]. With sufficient operation capital for production, Haier also offers trade credit financing service to the downstream SMEs. Moreover, in the underdeveloped countries or depressed financial market, as small size and startup companies have not enough collateral and credit history, trade credit is utilized even more widely [20,40,42].

Given the background of the asymmetric competing financial retailers, our study aims to examine the financing policies (trade credit versus vertical merger) of the manufacturer. Most of the previous studies examined the supply chain distribution channel decisions without considering the financial constraints of retailers (e.g., $[10,35])$. Our study bridges the manufacturer's financing strategy under retailer's competition circumstance. We will discuss the influence of retailers' competition and financial status on the manufacturer's distribution and financing decisions together with the associated equilibrium performances in this paper.

In detail, this study has three main research questions: (1) Should the manufacturer deselect or assist the capital-constrained retailer under the competitive retail market environment? (2) Which kind of financing service (trade credit versus vertical merger) will the manufacturer offer to the capital-constrained retailer? (3) How does the horizontal competition between retailers influence each player's equilibrium operational decisions and the financing strategy? To answer these questions, we formulate a two-echelon supply chain framework, which consists of a manufacturer and two asymmetric competing retailers basing on the Cournot mode, wherein one retailer is financial constrained, and the other one is fund-abundant.

The rest of paper is organized as follows. Section 2 reviews the relevant literature. Section 3 describes the basic framework of model. Section 4 analyzes the optimal operations and payoff of each participant under 
trade credit or vertical merger. Section 5 examines the manufacturer's optimal financing decision, and discusses the equilibrium condition for each financing strategy that is beneficial for both manufacturer's and capitalconstrained retailer's profits. In addition, the impact of competition intensity on the equilibrium strategies are analyzed. Section 6 presents numerical analysis. Section 7 concludes the study and suggests some future extensions. Appendix includes the proofs of propositions.

\section{Literature REVIEW}

Our work is relevant to two streams of research. One stream studies the manufacturer's distribution channel integration and vertical merger strategy in a supply chain. The other stream studies the trade credit financing policy for relieving buyer's capital distress. We review the two areas of studies in this section.

\subsection{Distribution channel integration and vertical merger strategy}

In recent years, considerable attention has been focused on the manufacturer's decision of whether to perform channel integration (e.g., $[1,47])$. Various pricing and advertising strategies are used in different channel structures [1] studied how one supplier uses partial forward integration to affect two retailers' strategic investments and found that partial forward integration will lead to greater investments in boosting product demand. Chen et al. [10] investigated the incentive of vertical mergers in a supply chain with suppliers, manufacturers and integrated firms. They proved that the vertical merger will lead to a lower price of final product and vertical mergers occur only when manufacturers' competitions are weak.

Dan et al. [15] investigated the impact of retail services on the manufacturer and retailer's pricing decisions under dual-channel. They found that in a decentralized dual-channel supply chain, the retailer sets a higher retail price for better service, while the manufacturer should decrease the direct sale price and increase the wholesale price when the retailer's service level is higher than a threshold. Karray and Amin [29] documented that with a low price competition and high advertising competition market, the cooperative advertising may not favorable for the retailers under multiple channels. Besides, the manufacturer's choice of channel structure in various competitive sales markets is studied. An earlier work of Moorthy [36] showed that the choice between decentralized or integrated channel is dependent on the demand substitutability and pricing strategies. $\mathrm{Wu}$ et al. [47] investigated that uncertain demand and production cost affect the channel structure, and the increased demand uncertainty results in the strength of integrated channel. Chiang et al. [13] examined supply chain's channel structures, and showed that direct channel could mitigate double marginalization and reduce the manufacturer's wholesale price to retailer, and further improve the profits of both retailer and manufacturer. Xu et al. [48] showed that if the manufacturer and retailer are risk-averse, the price will be lower than that in a risk-neutral dual-channel supply chain while the decentralized system is inefficient due to the vertical and horizontal competition. Liu et al. [34] developed a dual channel supply chain model with a manufacturer and several homogeneous retailers, and studied the impact of retailer's alliance on each player's profit in direct channel and retailer channel. They showed that forming an alliance is not always beneficial for retailers, and manufacturer's channel control capability largely affects the retailers' choices on alliance.

However, most of the previous studies about supply chain channels integration, like the above literature, examined the manufacturer's channel integration policy basing on the assumption that retailer has enough fund to purchase, and the retailer's capital status is ignored. Our study examines the manufacturer's channel strategy based on the case that one of its retailers has the shortage of money to procure, and under what condition that the manufacturer should develop a direct channel to complement the traditional retail channel.

Among the previous studies examined the channel integration with financing contract, "merger and acquisition" is an effective way. A number of studies showed that capital constraints is the main factor to motivate the firm's acquisition [17, 24,30,39]. Richards and Manfredo [39] examined the acquisitions among the 100 largest US agricultural cooperatives, and showed that the acquisition is mainly motivated by the capital constraints. If the shadow value of capital is higher, the cooperative is more likely to acquire and merger. Khatami et al. [30] found that the acquisition of financially constrained firms is beneficial for both the targets and bidders, and it 
is more possible for the target firm to be acquired when the firm owns less capital. Glock and Kim [21] studied a supply chain framework with one vendor and multiple competing retailers, and one retailer is merged by the vendor. They analyzed the condition that the merger would favor the vendor, retailer and the whole supply chain. Different from the above studies, we discuss the manufacturer's vertical merger as a financing mode under the retailer's competitive sales setting, and show how the competition influences the design of vertical integration contract.

\subsection{Trade credit financing}

Trade credit, as an internal financing channel, has been studied for several decades. One stream studies focus on the financial strength of trade credit. Earlier work such as Emery [16] shows that trade credit makes suppliers share a low transaction and financing cost with buyers. Gupta and Wang [22] examined the effect of finance charge in trade credit on the profits of suppliers and retailers. They presented that trade credit can be used to improve the efficiency of the entire supply chain. Chen and Wang [12] studied a trade credit contract with retailer's limited liability. They argued that limited liability initiates a retailer's higher ordering level, which creates value for a budget-constrained supply chain. Moreover, the superiority of trade credit was examined through the comparison between bank credit and trade credit. Babich et al. [2] compared the two financing channels: bank credit and trade credit under different settings, and showed that the firm should choose a financing channel with lower financing cost. Kouvelis and Zhao [31] showed that a risk-neutral supplier always financed the retailer at less than or equal to the risk-free rate, and the retailer preferred supplier financing to bank financing in an optimally structured trade credit contract. Zhang et al. [53] developed a trade credit model with considering manufacturer's account receivable risk attitude. They showed that trade credit for retailers depends on the manufacturer's attitude to risk and a risk-averse manufacturer will deliver less than the retailer's optimal order quantity. Chen [11] showed that trade credit outperforms bank credit for all members in a wholesale price contract, and the trade credit has a unique financing equilibrium.

The other stream studies explain the operational role that trade credit plays in supply chain. For example, Lee and Stowe [32] argued that because the buyers have little information about the product and suppliers, and the product is difficult to assess, trade credit permits the buyers to verify the quality before submitting payments. And suppliers can also use trade credit to signal quality of product. Brennan et al. [5] showed that with the decreased production cost of adulterated products, trade credit will reduce the supplier's incentive to cheat. They also compared the buyer's profit under trade credit and inspection mechanism, and showed that the dominance of either mechanism depends on the factors that include inspection cost relative to inspection accuracy, buyer's liability, the rate at which customers discover adulteration, and unadulterated/adulterated product cost gap. Yang and Birge [50] studied the risk-sharing role of trade credit that retailer partially shares the demand risk with the supplier to improve the supply chain's efficiency.

Most existing literature modeled the trade credit problem in a supply chain framework, where the manufacturer uses only one distribution channel and permits the retailer's delay payment for the ordering (e.g., [7,31]). However, market competition has significant impact on the usage of trade credit [14]. Among the studies examining the influence of market competition on trade credits, Petersen and Rajan [37] showed that the manufacturer is not willing to use trade credit when many manufacturers compete for the retailers. Chod et al. [14] observed the negative relations between the prevalence of trade credit and competition among suppliers, because using trade credit results in a "free-rider" problem that a financially constrained customer could share the trade credit from one manufacturer but use the cash to purchase from other manufacturers. On the contrary, Fabbri and Klapper [18] illustrated that the more competitive the suppliers faces, the more often trade credit would be used. Barrot [3] showed that a financially powerful firm would not like to offer a long trade credit term. Peura et al. [38] examined the horizontal effect of trade credit on suppliers who perform the Bertrand competition, and found that trade credit softened the price competition among suppliers. However, the above studies analyzed how the competition among manufacturers influences their willingness to offer trade credit financing service to downstream retailers, and the competitive sales environment that retailers face is ignored. In this paper, we 
examine each player's operational strategy under trade credit with considering retailers' competitive ordering behavior, and discuss the impact of retailers' competition intensity on the trade credit financing policy.

Among the few papers examining trade credits under retailers' competition, Yang et al. [49] developed a supply chain with a supplier and two capital-constrained retailers, and both retailers were able to receive the trade credits from the manufacturer, external bank financing, or equity financing. They discussed each player's operational strategy based on how many retailers are permitted to be financed through trade credit, and showed that when competition becomes increasingly fierce, the manufacturer will merge with one retailer, and the deselected retailer may utilize bank combined with equity financing channel to return the supply chain. Different to their study, we discuss the case that a single retailer has financial constraints and competes with the other fund-abundant retailer in sales market, and the manufacturer can offer trade credit or vertical merger to the capital-constrained retailer to release the retailer's financial constraints. In our paper, we examine the manufacturer's optimal choice on the equilibrium financing strategy between trade credit and vertical merger. In addition, we investigate the impact of retailer's competition on the decisions and performance of supply chain under different financing contract.

In summary, the contributions of our study mainly lie on the following aspects. First, most of previous papers (e.g., $[15,47])$ have studied the channel integration without considering the buyer's financial constraints. We contribute by bridging the channel strategy with financing modes in supply chain, and give out the conditions when the manufacturer should assist the downstream retailer who has financial constraints to purchase. Second, our study enriches the research on the trade credit in supply chain finance. We examine the trade credit financing contract based on the retailers' competitive setting, which has been rarely discussed in previous research. Also, we compare the effect of retailers' competition on equilibrium of financing channels: trade credit and vertical merger.

\section{MODEL SET UP}

We consider a two-echelon supply chain with a manufacturer (denoted by $M$, referred to herein as "he") and two duopolistic asymmetric retailers (denoted by $R_{1}$ and $R_{2}$ ) with different working capital. Without loss of generality, we assume that retailer $R_{1}$ lacks ordering capital, and the competitor $R_{2}$ is not capital-constrained. For the simplicity of modeling, we assume the retailer $R_{1}$ 's initial budget is zero. The manufacturer has sufficient working capital to cover the retailers' ordering and needs to decide whether to finance the retailer $R_{1}$. We assume $R_{1}$ cannot use external financing [49]. Thus, if manufacturer deselects $R_{1}$, he sells product through $R_{2}$ and the retailer $R_{1}$ quit the market for lacking capital. If the manufacturer assist $R_{1}$, he can choose merger with $R_{1}$ or trade credit. When the retailer $R_{1}$ is vertically merged by the manufacturer, they perform as a strategic alliance to compete with $R_{2}$ directly. Otherwise, the manufacturer can provide trade credit to assist $R_{1}$.

The manufacturer and $R_{1}$ should sign a contract to clarify the division of profit if merger happens. If manufacturer provides trade credit to $R_{1}$, there exists capital opportunity cost in the period of $R_{1}$ 's delay payment. We assume the financing cost per unit capital is lower than the maximum marginal profit of product (i.e., $\left.I_{m}<(\alpha-c) / c\right)$.

Two retailers perform the Cournot quantity competition during product sales process and the customers are able to purchase the product from either of the two retailers. We assume the demand of each retailer is a general linear function of its own sale price and the rival's price, which is commonly adopted in previous studies (e.g., $[4,19,27,43,45,46,52])$. Thus, the inverse demand function of retailers can be expressed as,

$$
p_{i}=\alpha-\beta\left(q_{i}+\gamma q_{3-i}\right), \quad i=1,2,
$$

where $q_{i}, q_{3-i}$ are endogenous variables that respectively represent the order quantity of two retailers $R_{i}$ and $R_{3-i}$.

When the manufacturer deselect retailer $R_{1}$ and sells only to $R_{2}$, according to (3.1), we obtain the inverse demand function for $R_{2}, p_{2}=\alpha-\beta q_{2}$. 
TABLE 1. List of parameters and notation.

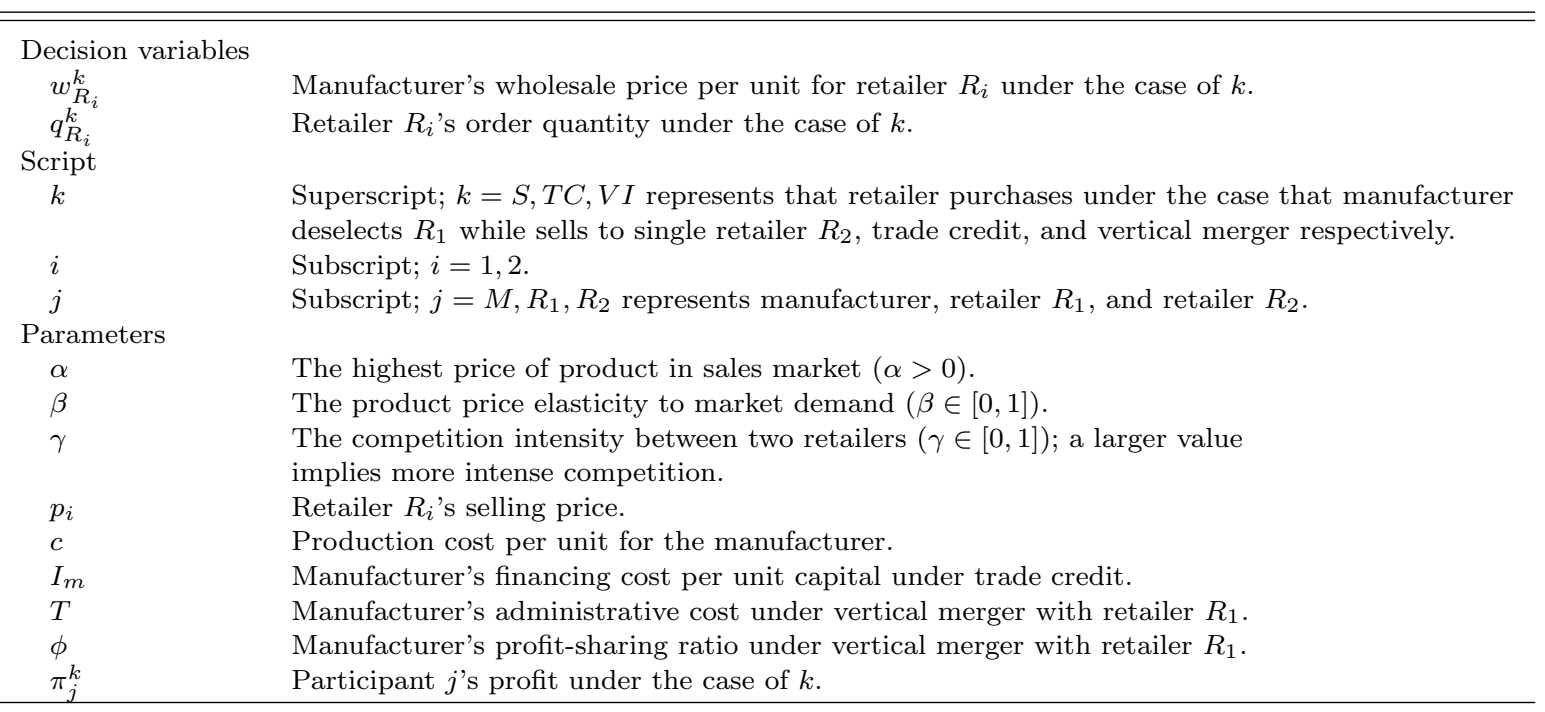

In this paper, we study the behavior of each participant in the supply chain through a dynamic game theoretical model, where the retailers perform the Cournot competition during product sales process while the manufacturer and the retailer interact in Stackelberg game. To be specific, the time sequence of game is as follows:

(1) the manufacturer determines whether to assist retailer $R_{1}$ and distribute the product;

(2) when choosing to offer financial help to $R_{1}$, the manufacturer decides merge with $R_{1}$ or provide trade credit to $R_{1}$;

(3) the manufacturer sets wholesale price(s) by taking into account the channel strategy and financial type, then each retailer decides the ordering quantity, if any.

For ease of exposition, the implications of parameters and notation are listed in Table 1.

\section{EQUILIBRIUM ANALYSIS}

In this section, we examine each player's equilibrium strategy under different settings. In the benchmark model, manufacturer only sells to retailer $R_{2}$, while retailer $R_{1}$ will not participate in the game for lack of capital. We discuss the manufacturer's pricing and retailer $R_{2}$ 's ordering decisions. If the capital-constrained retailer $R_{1}$ is financed, the manufacturer provides trade credit financing to retailer $R_{1}$ or vertical merger with retailer $R_{1}$. We discuss two retailers' equilibrium order quantities and manufacturer's pricing strategy under two financing policies.

\subsection{Benchmark model}

In this case, manufacturer would not provide any financing service to retailer $R_{1}$, and only sells to retailer $R_{2}$. Then the manufacturer performs a single distribution channel, and the transaction between the manufacturer and retailer $R_{2}$ follows the normal Stackelberg game in one-manufacturer-one-retailer supply chain. Thus, the retailer $R_{2}$ 's profit is

$$
\pi_{R_{2}}^{S}=\left(\alpha-\beta q_{R_{2}}^{S}-w_{R_{2}}^{S}\right) q_{R_{2}}^{S},
$$

and the manufacturer's profit is

$$
\pi_{M}^{S}=\left(w_{R_{2}}^{S}-c\right) q_{R_{2}}^{S} .
$$


With backward induction approach, the players' equilibrium decisions and profits are characterized in Proposition 4.1 as follows:

Proposition 4.1. Under single distribution channel, manufacturer's optimal wholesale price is $w_{R_{2}}^{S^{*}}=\frac{\alpha+c}{2}$, and retailer $R_{2}$ 's ordering decision is $q_{R_{2}}^{S^{*}}=\frac{\alpha-c}{4 \beta}$. Two participants' profits are $\pi_{R_{2}}^{S}=\frac{(\alpha-c)^{2}}{16 \beta}, \pi_{M}^{S}=\frac{(\alpha-c)^{2}}{8 \beta}$.

Proof. See Appendix A.

Proposition 4.1 shows that as there exists none competition in the consumer market, both the optimal order quantity and profit do not correlate with $\gamma$. Based on Proposition 4.1, manufacturer should decide whether to finance retailer $R_{1}$ or not.

\subsection{Trade credit financing for the capital-constrained retailer}

When the manufacturer provides trade credit service to finance the capital-constrained retailer, it allows the retailer $R_{1}$ to purchase with delay payment. The retailer $R_{2}$ pays off its ordering immediately. For $R_{1}$ 's delay payment, there exists a capital opportunity cost for the manufacturer. Considering retailers' competitive sales environment, the sequence of events is as follows:

First, the manufacturer sets the profit maximizing wholesale price as $w_{R_{1}}^{T C}$ by considering the trade credit contract for retailer $R_{1}$. Meanwhile, it sells to retailer $R_{2}$ with another wholesale price $w_{R_{2}}^{T C}$. Second, the two retailers submit their orderings independently and simultaneously in Cournot competition model. The manufacturer distributes two retailers' orderings at once, and retailer $R_{2}$ pays to the manufacturer immediately. Third, at the end of sales season, the retailers gain the sales revenue from customers, and retailer $R_{1}$ pays its ordering to manufacturer. Thus, combined the inverse demand function equation (3.1), the retailer $R_{i}$ 's profit is

$$
\begin{aligned}
& \pi_{R_{1}}^{T C}=\left[\alpha-\beta\left(q_{R_{1}}^{T C}+\gamma q_{R_{2}}^{T C}\right)-w_{R_{1}}^{T C}\right] q_{R_{1}}^{T C}, \\
& \pi_{R_{2}}^{T C}=\left[\alpha-\beta\left(q_{R_{2}}^{T C}+\gamma q_{R_{1}}^{T C}\right)-w_{R_{2}}^{T C}\right] q_{R_{2}}^{T C} .
\end{aligned}
$$

The manufacturer receives the payment from retailer $R_{2}$ when he delivers the products, and thus the gaining from retailer $R_{2}$ is $\left(w_{R_{2}}^{T C}-c\right) q_{R_{2}}^{T C}$. Because the retailer $R_{1}$ has not submitted the funds of goods until the end of sales season, the manufacturer can not turn around the expenditure of production $c q_{R_{1}}^{T C}$ instantly, and thus takes the financing $\operatorname{cost} c I_{m} q_{R_{1}}^{T C}$ for $R_{1}$ 's ordering quantity. Hence, the manufacturer's profit is as follows:

$$
\pi_{M}^{T C}=w_{R_{1}}^{T C} q_{R_{1}}^{T C}+w_{R_{2}}^{T C} q_{R_{2}}^{T C}-c\left(q_{R_{1}}^{T C}+q_{R_{2}}^{T C}\right)-c I_{m} q_{R_{1}}^{T C} .
$$

Taking the backward induction approach, we have the manufacturer's optimal pricing decision, the equilibrium ordering amounts of two retailers, and each participant's profit in trade credit financing framework in Proposition 4.2 .

Proposition 4.2. (1) $w_{R_{1}}^{T C^{*}}=\frac{\alpha+c\left(1+I_{m}\right)}{2}, w_{R_{2}}^{T C^{*}}=\frac{\alpha+c}{2}$; (2) $q_{R_{1}}^{T C^{*}}=\frac{(2-\gamma)(\alpha-c)-2 c I_{m}}{2 \beta\left(4-\gamma^{2}\right)}, q_{R_{2}}^{T C^{*}}=\frac{(2-\gamma)(\alpha-c)+\gamma c I_{m}}{2 \beta\left(4-\gamma^{2}\right)}$; (3) $\pi_{R_{1}}^{T C}=\beta\left(q_{R_{1}}^{T C^{*}}\right)^{2}, \pi_{R_{2}}^{T C}=\beta\left(q_{R_{2}}^{T C^{*}}\right)^{2}, \pi_{M}^{T C}=\frac{(2-\gamma)(\alpha-c)\left(\alpha-c-c I_{m}\right)+\left(c I_{m}\right)^{2}}{2 \beta\left(4-\gamma^{2}\right)}$.

Proof. See Appendix B.1.

Proposition 4.2 shows that the wholesale price for retailer $R_{1}$ is higher in trade credit contract than that for retailer $R_{2}$ because manufacturer will increase the wholesale price to offset the financing cost due to $R_{1}$ 's delay payment in trade credit contract. And from the optimal equilibrium ordering decisions of retailers, it is straightforward to derive that manufacturer's capital cost leads to lower order quantity and profit for retailer $R_{1}$ relative to retailer $R_{2}$. Note, if retailer $R_{1}$ has no capital constraints, manufacturer will not offer any financing service to both of two retailers, and then the manufacturer's financing cost $I_{m}$ equals zero. Thus, the two retailers get the same wholesale, and share the demand of product equally, which results in an equal profit in the competitive sales market. 
Corollary 4.3. (1) $\frac{\mathrm{d} q_{R_{1}}^{T C^{*}}}{\mathrm{~d} \gamma}<0$; (2) If $I_{m}<\frac{\alpha-c}{5 c}$, or $\frac{\alpha-c}{5 c} \leq I_{m}<\frac{\alpha-c}{c}$ and $\gamma \in\left[0, \frac{2\left[\alpha-c-\sqrt{c I_{m}\left(2(\alpha-c)-c I_{m}\right)}\right]}{\alpha-c-c I_{m}}\right]$ then $\frac{\mathrm{d} q_{R_{2}}^{T C^{*}}}{\mathrm{~d} \gamma}<0$; if $\frac{\alpha-c}{5 c} \leq I_{m}<\frac{\alpha-c}{c}$ and $\gamma \in\left[\frac{2\left[\alpha-c-\sqrt{c I_{m}\left(2(\alpha-c)-c I_{m}\right)}\right]}{\alpha-c-c I_{m}}, 1\right], \frac{\mathrm{d} q_{R_{2}}^{T C^{*}}}{\mathrm{~d} \gamma}>0 ;(3) \frac{\mathrm{d}\left(q_{R_{1}}^{T C}+q_{R_{2}}^{T C^{*}}\right)}{\mathrm{d} \gamma}<0$.

Proof. See Appendix B.2.

Corollary 4.3 shows that under trade credit, retailer $R_{1}$ 's order quantity decreases with competition intensity $\gamma$. However, if the financing cost of trade credit exceeds the limit of $\frac{\alpha-c}{5 c}$, the retailer $R_{1}$ 's optimal order quantity is largely restricted, which may conversely leads to retailer $R_{2}$ to seize more shares in sales market, and it is more favorable for $R_{2}$ in more intensified competitive environment. Thus, the order quantity of $R_{2}$ is likely to increase with $\gamma$, which is larger than $\frac{2\left[\alpha-c-\sqrt{c I_{m}\left(2(\alpha-c)-c I_{m}\right)}\right]}{\alpha-c-c I_{m}}$. However, as a whole, the competition intensity $\gamma$ restrains the manufacturer's whole sales quantity.

Corollary 4.4. (1) $\frac{\mathrm{d} \pi_{R_{1}}^{T C}}{\mathrm{~d} \gamma}<0$; (2) If $I_{m}<\frac{\alpha-c}{5 c}$, then $\frac{\mathrm{d} \pi_{R_{2}}^{T C}}{\mathrm{~d} \gamma}<0$; and if $\frac{\alpha-c}{5 c} \leq I_{m}<\frac{\alpha-c}{c}$, then $\pi_{R_{2}}^{T C}$ decreases with $\gamma$ when $\gamma \in\left[0, \frac{2\left[\alpha-c-\sqrt{c I_{m}\left(2(\alpha-c)-c I_{m}\right)}\right]}{\alpha-c-c I_{m}}\right]$ and increases with $\gamma$ when $\gamma \in\left[\frac{2\left[\alpha-c-\sqrt{c I_{m}\left(2(\alpha-c)-c I_{m}\right)}\right]}{\alpha-c-c I_{m}}, 1\right] ;(3)$ $\frac{\mathrm{d} \pi_{M}^{T C}}{\mathrm{~d} \gamma}<0 ;$

Proof. See Appendix B.3.

In line with Proposition 4.1, the retailers' profits and order quantities have the same tendencies with $\gamma$, which is shown in Corollary 4.3, and the horizontal competition between retailers is also detrimental to manufacturer's profit.

\subsection{Vertical merger with the capital-constrained retailer}

Besides trade credit, another effective method to assist the capital-constrained retailer is to acquisition and merger, where the manufacturer can collaborate with downstream retailer [17]. Under this strategy, retailer $R_{1}$ is merged to be an alliance as the direct sales store of manufacturer, and manufacturer incurs a fixed administrative fee or setup cost of integration to open a direct sales store [8,33]. Furthermore, the manufacturer and retailer share the profit of the direct sales. In this paper, we assume a vertical merger contract should be signed before merger, specifically, the manufacturer can get $\phi$ share of the profit while the remaining part belongs to the $R_{1}$. Under this circumstance, the manufacturer distributes its product from direct channel and retailer $R_{2}$ 's channel, and the competition between two retailers actually transfers to the competition between the manufacturer and the fund-abundant retailer $R_{2}$. The sequence of events is as follows.

First, the manufacturer decides a wholesale price to retailer $R_{2}$ and disburses a fixed administrative cost $T$ to merge retailer $R_{1}$. Then, the equilibrium order quantities are simultaneously decided upon manufacturer and retailer $R_{2}$, and $R_{2}$ takes a prompt payment of purchase with manufacturer, while retailer $R_{1}$ is an affiliate of the manufacturer. After realizing the market demand, the manufacturer shares the profit with retailer $R_{1}$ according to a given ratio $\phi$ in the vertical merger contract. Derived from equation (3.1), the retailer $R_{2}$ 's profit is

$$
\pi_{R_{2}}^{V I}=\left[\alpha-\beta\left(q_{R_{2}}^{V I}+\gamma q_{R_{1}}^{V I}\right)-w_{R_{2}}^{V I}\right] q_{R_{2}}^{V I} .
$$

The manufacturer's profit is influenced by three parts: one is the gaining from the payment of retailer $R_{2}$, the second is the share of profit with ratio $\phi$ due to the direct sales for the vertical merger, and the last is the administrative fee $T$ for the merger with $R_{1}$. Thus, the manufacturer's profit is

$$
\pi_{M}^{V I}=\left(w_{R_{2}}^{V I}-c\right) q_{R_{2}}^{V I}+\phi\left[\alpha-\beta\left(q_{R_{1}}^{V I}+\gamma q_{R_{2}}^{V I}\right)-c\right] q_{R_{1}}^{V I}-T
$$


Meanwhile, the retailer $R_{1}$ should conform with manufacturer's direct sales plan, and has no choice to make decision for the operations. Thus, the retailer $R_{1}$ 's profit is the commission that depends on the ratio $1-\phi$ from the manufacturer's direct sales mode as following:

$$
\pi_{R_{1}}^{V I}=(1-\phi)\left[\alpha-\beta\left(q_{R_{1}}^{V I}+\gamma q_{R_{2}}^{V I}\right)-c\right] q_{R_{1}}^{V I} .
$$

Solving the supply chain's equilibrium ordering problem as equations (4.6) and (4.7), and then substitute into manufacturer's pricing problem as equation (4.7), we can obtain the manufacturer and retailer $R_{2}$ 's optimal decisions and each participant's profit as shown in following proposition.

Proposition 4.5. (1) $w_{R_{2}}^{V I^{*}}=\frac{\left(4-\gamma^{2}\right)[2(\alpha+c)-\gamma(\alpha-c)]+2 \gamma \phi[2(\alpha-c)-\alpha \gamma]}{2\left[8-\gamma^{2}(2+\phi)\right]} ;$ (2) $q_{R_{1}}^{V I^{*}}=\frac{(\alpha-c)(2-\gamma)(4+\gamma)}{2 \beta\left[8-\gamma^{2}(2+\phi)\right]}, q_{R_{2}}^{V I^{*}}=$ $\frac{(\alpha-c)[2-\gamma(1+\phi)]}{\beta\left[8-\gamma^{2}(2+\phi)\right]} ;(3) \pi_{R_{1}}^{V I}=(1-\phi) \beta\left(q_{R_{1}}^{V I^{*}}\right)^{2}, \pi_{R_{2}}^{V I}=\beta\left(q_{R_{2}}^{V I^{*}}\right)^{2}, \pi_{M}^{V I}=\frac{(\alpha-c)^{2}(2-\gamma)(2-\gamma+4 \phi)}{4 \beta\left[8-\gamma^{2}(2+\phi)\right]}-T$.

Proof. See Appendix C.1.

Proposition 4.5 shows that the competition intensity $\gamma$ and profit sharing proportion $\phi$ in the vertical merger of retailer $R_{1}$ influence the manufacturer's optimal wholesale price for retailer $R_{2}$. It is mainly because that the competition between manufacturer and retailer $R_{2}$ will result in an equilibrium sales share in the competitive market. Also, the competition and profit sharing proportion $\phi$ affect the optimal equilibrium order quantity of retailer $R_{2}$ and each member's profit. However, if the administrative cost $T$ is larger than $\frac{(\alpha-c)^{2}(2-\gamma)(2-\gamma+4 \phi)}{4 \beta\left[8-\gamma^{2}(2+\phi)\right]}$, the manufacturer's profit becomes negative, which will lead the manufacturer to abandon the integration of retailer $R_{1}$. Thus, the manufacturer can balance the gaining and cost in the vertical merger, and decides whether to take over the $R_{1}$ according to Proposition 4.5.

Corollary 4.6. (1) $\frac{\partial w_{R_{2}}^{V I^{*}}}{\partial \phi}>0 ;(2) \frac{\partial q_{R_{1}}^{V I *}}{\partial \phi}>0, \frac{\partial q_{R_{2}}^{V I *}}{\partial \phi}<0$; (3) $\frac{\partial \pi_{R_{1}}^{V I}}{\partial \phi}<0, \frac{\partial \pi_{R_{2}}^{V I}}{\partial \phi}<0, \frac{\partial \pi_{M}^{V I}}{\partial \phi}>0$.

Proof. See Appendix C.2.

Corollary 4.6 shows that the profit sharing ratio in vertical merger has a positive effect on wholesale price for retailer $R_{2}$. That is, the more profit ratio that the manufacturer shares, the higher wholesale price that should be set for the fund-abundant retailer. Because of the more shares that manufacturer gets from the merger, the more powerful he becomes to compete with retailer $R_{2}$ for more shares in the consumer market. Thus, increasing the wholesale price to $R_{2}$ will decrease the $R_{2}$ 's ordering volume, and then improve the sales of retailer $R_{1}$, which is steered by the manufacturer. Moreover, Corollary 4.6 also shows that as profit-sharing ratio $\phi$ increases, the profit of two retailers decreases, while the profit of manufacturer increases.

Let $\eta(\gamma)=32(1-\phi)+16 \gamma \phi+\gamma^{4}(2+\phi)-4 \gamma^{2}\left(4+\phi+\phi^{2}\right)$, we have Corollary 4.7.

Corollary 4.7. Given a certain value of $\phi$, (1) if $\eta(\gamma)>0$, then $\frac{\partial w_{R_{2}}^{V I^{*}}}{\partial \gamma}<0$; if $\eta(\gamma) \leq 0$, $\frac{\partial w_{R_{2}}^{V I^{*}}}{\partial \gamma} \geq 0$; (2) $\frac{\partial q_{R_{1}}^{V I *}}{\partial \gamma} \geq 0$ only if $\frac{2}{7} \leq \phi \leq 1$ and $\gamma \in\left[\frac{4(1+\phi)-2 \sqrt{2 \phi(2 \phi+3)}}{2+\phi}, 1\right]$, otherwise, $\frac{\partial q_{R_{1}}^{V I *}}{\partial \gamma}<0 ; \frac{\partial q_{R_{2}}^{V I *}}{\partial \gamma}<0 ;$ (3) $\frac{\partial \pi_{R_{1}}^{V I}}{\partial \gamma} \geq 0$ only if $\frac{2}{7} \leq \phi \leq 1$ and $\gamma \in\left[\frac{4(1+\phi)-2 \sqrt{2 \phi(2 \phi+3)}}{2+\phi}, 1\right]$, otherwise, $\frac{\partial \pi_{R_{1}}^{V I}}{\partial \gamma}<0 ; \frac{\partial \pi_{R_{2}}^{V I}}{\partial \gamma}<0, \frac{\partial \pi_{M}^{V I}}{\partial \gamma}<0$.

Proof. See Appendix C.3.

As shown in Corollary 4.7, in the vertical merger of $R_{1}$, the impact of $\gamma$ on the wholesale price for retailer $R_{2}$ is dependant on profit sharing portion $\phi$. Given the complexity of $\eta(\gamma)$, we will use some numerical studies to show how the $\gamma$ influences the manufacturer's pricing decision for retailer $R_{2}$ in Section 6 . Furthermore, when $\phi \geq \frac{2}{7}$ and $\gamma$ is larger than the threshold (i.e., $\gamma \geq \frac{4(1+\phi)-2 \sqrt{2 \phi(2 \phi+3)}}{2+\phi}$ ), the sales volume in direct sales channel will increase with $\gamma$, which is beneficial for retailer $R_{1}$. Under vertical merger, the manufacturer monitors the 
direct sales channel and struggles for market shares with retailer $R_{2}$, and thus the more goods distributed in the direct sales channels, the more profit $R_{1}$ will make with a suitable profit sharing ratio $\phi$ in vertical merger contract. However, the intensified competition will largely impel retailer $R_{2}$ to make a less ordering, and then the corresponding profit is reduced. Meanwhile, the competition is also not favorable for the manufacturer to make a larger profit.

Corollary 4.8. $q_{R_{1}}^{V I^{*}}-q_{R_{2}}^{V I^{*}}>0$ and $\frac{\partial\left(q_{R_{1}}^{V I^{*}}-q_{R_{2}}^{V I^{*}}\right)}{\partial \phi}>0, \frac{\partial\left(q_{R_{1}}^{V I^{*}}-q_{R_{2}}^{V I^{*}}\right)}{\partial \gamma}>0$.

Proof. See Appendix C.4.

Corollary 4.8 shows that if manufacturer merges the retailer $R_{1}$ and distributes the product to retailer $R_{2}$ as well, the direct sales channel shares more market demand than traditional channel from retailer $R_{2}$. Moreover, with increasing the profit-sharing ratio $\phi$ or competition intensity $\gamma$, direct-sales channel will share more sales quantity, and the disparity of sales amount will be enlarged in the manufacturer's sales channels for two retailers.

Corollary 4.9. $p_{R_{1}}^{V I^{*}}-p_{R_{2}}^{V I^{*}}<0$ and $\frac{\partial\left(p_{R_{1}}^{V I^{*}}-p_{R_{2}}^{V I^{*}}\right)}{\partial \phi}<0, \frac{\partial\left(p_{R_{1}}^{V I^{*}}-p_{R_{2}}^{V I^{*}}\right)}{\partial \gamma}>0$.

Proof. See Appendix C.5.

Corollary 4.9 characterizes the comparison of sales price in the consumer market under two distribution channels. That is, compared with the retailer $R_{2}$, the manufacturer will set a lower price for the direct-sales channel where $R_{1}$ is merged. And with more intensified competition between two channels, the distinction of retailing price of two retailers increases. If the manufacturer shares less profit from vertical merger, the distinction of retailing price of two retailers becomes even more significant.

\section{COMPARISON FOR EACH PARTICIPANT'S PROFIT UNDER VARIOUS FINANCING MODES}

In this section, we first examine whether the manufacturer will assist retailer $R_{1}$. If manufacturer would like to solve $R_{1}$ 's lack of ordering fund, we then discuss how to choose the financing form, and under what condition that trade credit dominates vertical merger in terms of the profits of both manufacturer and retailer $R_{1}$. Moreover, we compare the impact of different channels on retailer $R_{2}$ 's profit.

\subsection{Choice of finance capital-constrained retailer}

In this subsection, we compare the manufacturer's pricing strategies and the wholesales quantity under different settings, and we also examine the condition that the manufacturer chooses to finance the retailer $R_{1}$.

Lemma 5.1. $w_{R_{1}}^{T C^{*}}>w_{R_{2}}^{T C^{*}}=w_{R_{2}}^{S^{*}}>w_{R_{2}}^{V I^{*}}$.

Proof. See Appendix D.1.

Lemma 5.1 illustrates the relationship of manufacturer's wholesale price to two retailers under different sales circumstances. Due to the capital cost, manufacturer sets the highest price for retailer $R_{1}$ under trade credit, which is higher than the price for retailer $R_{2}$, which is the same under trade credit and single selling channel to retailer $R_{2}$. Furthermore, retailer $R_{2}$ can purchase from manufacturer at the lowest price if manufacturer merges retailer $R_{1}$.

Let $q_{I}$ denote the whole order quantity of two retailers in supply chain. The variable $q_{I}$ represents the manufacturer's whole sales volume. Thus, we have

Lemma 5.2. $q_{R_{2}}^{S^{*}}<q_{I}^{T C^{*}}<q_{I}^{V I^{*}}$.

Proof. See Appendix D.2. 
Lemma 5.2 shows that manufacturer sells more products from two retailers than that under single channel with retailer $R_{2}$. In addition, vertical merger of retailer $R_{1}$ increases the market demand more largely than just using trade credit, and thus the vertical merger increases the manufacturer's sales amount.

Proposition 5.3. (1) $\pi_{M}^{T C}>\pi_{M}^{S}$ holds if $I_{m}<\frac{(2-\gamma)(\alpha-c)}{2 c}$. (2) $\pi_{M}^{V I}>\pi_{M}^{S}$ holds if $0<T<\frac{\phi(4-\gamma)^{2}-4 \gamma(2-\gamma)}{8 \beta\left[8-\gamma^{2}(2+\phi)\right]}$.

Proof. See Appendix D.3.

As shown in Proposition 5.3, as long as the capital cost rate $I_{m}$ is not so large to some extent (i.e., $\left.I_{m}<\frac{(2-\gamma)(\alpha-c)}{2 c}\right)$, the manufacturer always prefers to provide trade credit financing to retailer $R_{1}$, because manufacturer can obtain more payoffs under distribution channels with two retailers than that under single channel with retailer $R_{2}$. This also explains why the trade credit is popular for the business between vendor and buyer. Meanwhile, only with a lower administrative cost than some level (i.e., $\left.T<\frac{\phi(4-\gamma)^{2}-4 \gamma(2-\gamma)}{8 \beta\left[8-\gamma^{2}(2+\phi)\right]}\right)$, the manufacturer would like to integrate the retailer $R_{1}$. Thus, Proposition 5.3 gives the condition that the manufacturer chooses to finance capital-constrained retailer $R_{1}$ in the supply chain.

Corollary 5.4. If $0<T<\frac{9 \phi-4}{8 \beta(6-\phi)}$, then $\pi_{M}^{V I}>\pi_{M}^{S}$ holds for any $\gamma \in[0,1]$.

Proof. See Appendix D.4.

Corollary 5.4 shows that if the manufacturer shares the profit with proportion $\phi$ that is larger than $\frac{4}{9}$, and acquisition cost $T$ is not larger than some extent (i.e., $\left.T<\frac{9 \phi-4}{8 \beta(6-\phi)}\right)$, merging retailer $R_{1}$ as the direct-sales stores is always better than only selling to retailer $R_{2}$. Although there exists competition among manufacturer and strong retailer $R_{2}$, the manufacturer would like to make the retailer $R_{1}$ to be an integrated firm and set a suitable vertical merger contract to maximize the profit of its own.

\subsection{Choice of financing channel}

In this section, we compare the profits of both parties in different financing contracts (trade credit versus vertical merger) separately. Also, to investigate the financing channel equilibrium, we find the range of profit-sharing ratio in vertical merger that benefits for financier and lenders. Finally, we analyze the impact of competition intensity between retailers on each player's optimal operations decision and the evolution of equilibrium financing choice.

Lemma 5.5. There exists only one root $\phi_{0} \in(0,1)$ such that $\pi_{R_{1}}^{T C}=\pi_{R_{1}}^{V I}$. If $\phi \in\left[0, \phi_{0}\right], \pi_{R_{1}}^{T C} \leq \pi_{R_{1}}^{V I}$; while if $\phi \in\left(\phi_{0}, 1\right], \pi_{R_{1}}^{T C}>\pi_{R_{1}}^{V I}$.

Proof. See Appendix E.1.

In line with Lemma 5.5 , given a $\phi$ that is not larger than $\phi_{0}$, that is, if retailer $R_{1}$ shares profit with a ratio that is not less than $1-\phi_{0}$, vertical merger outperforms trade credit for capital-constrained retailer $R_{1}$.

Lemma 5.6. If $T<\frac{(\alpha-c)^{2}(2-\gamma)\left(8-4 \gamma+\gamma^{3}\right)+2\left(8-3 \gamma^{2}\right) c I_{m}\left[(2-\gamma)(\alpha-c)-c I_{m}\right]}{4 \beta\left(8-3 \gamma^{2}\right)\left(4-\gamma^{2}\right)}$, there exists only one root $\phi_{1} \in(0,1)$ such that $\pi_{M}^{T C}=\pi_{M}^{V I}$. If $\phi \in\left[0, \phi_{1}\right], \pi_{M}^{T C} \geq \pi_{M}^{V I}$; while if $\phi \in\left(\phi_{1}, 1\right], \pi_{M}^{T C}<\pi_{M}^{V I}$.

Proof. See Appendix E.2.

Lemma 5.6 shows that with a suitable management cost $T$, a profit-sharing ratio $\phi$ that is higher than $\phi_{1}$ induces the manufacturer to merge with retailer $R_{1}$. Hence, if manufacturer maximizes his own profit, he will set a high $\phi(\phi \rightarrow 1)$ to get most of profit in direct sales channel. The manufacturer also needs to consider the profits of both parties in the financing contract: how to set a profit-sharing ratio in order to make vertical merger to be better than trade credit. Thus, combing Lemma 5.5 and Lemma 5.6, we examine the range of $\phi$ that benefits both players as the following proposition. 
Proposition 5.7. If $\phi_{1} \leq \phi_{0}$, then when $\left[\phi_{1}, \phi_{0}\right], \pi_{R_{1}}^{V I} \geq \pi_{R_{1}}^{T C}$ and $\pi_{M}^{V I} \geq \pi_{M}^{T C}$ hold simultaneously (i.e., vertical merger outperforms trade credit financing); If $\phi_{1}>\phi_{0}$, then when $\left[\phi_{0}, \phi_{1}\right]$ trade credit financing outperforms vertical acquisition.

Proof. See Appendix E.3.

According to Proposition 5.7, there always exists a range of profit-sharing ratio $\phi$ that benefits for both parties in vertical merger. The financing choice between trade credit and vertical merger depends on $\phi_{0}$ and $\phi_{1}$, which correlates to retailers' competition intensity $\gamma$. From Corollary 4.6, we can see that the parameter $\phi$ has a positive effect on the payoff of manufacturer but negative impact on retailer $R_{1}$ 's profit. Thus, the two financing channels (trade credit and vertical merger) will be balanced along with $\phi$. Furthermore, we examine the equilibrium evolution of financing channels in terms with competition intensity $\gamma$ in the Proposition 5.8.

Let $X(\gamma)=\frac{\left[(\alpha-c)(2-\gamma)-2 c I_{m}\right]\left[(\alpha-c)(2-\gamma)^{2}+4 \gamma c I_{m}\right]}{\left(4-\gamma^{2}\right)^{3}}-\frac{2(\alpha-c)^{2}(2-\gamma)(4+\gamma)\left(1-\phi_{0}\right)\left[8-8 \gamma\left(1+\phi_{0}\right)+\gamma^{2}\left(2+\phi_{0}\right)\right]}{\left[8-\gamma^{2}\left(2+\phi_{0}\right)\right]^{3}}$, and $Y(\gamma)=$ $\left[-2 \alpha(2-\gamma)^{3}(2+\gamma)+\alpha \gamma \phi_{0}\left(16-(6-\gamma) \gamma^{2}\right)+c\left(32-\gamma^{4}\left(2+\phi_{0}\right)-16 \gamma\left(2+\phi_{0}+I_{m}\right)+2 \gamma^{3}\left(4+3 \phi_{0}+I_{m}(2+\right.\right.\right.$ $\left.\left.\left.\left.\phi_{0}\right)\right)\right)\right]\left[-\alpha \phi_{0}(2-\gamma)(4+\gamma)+c\left((2-\gamma)(4+\gamma) \phi_{0}-I_{m}\left(8-\gamma^{2}\left(2+\phi_{0}\right)\right)\right)\right]$, we have the impact of $\gamma$ on the equilibrium evolution of each financing channel as follows.

Proposition 5.8. (1) $\frac{\mathrm{d} \phi_{0}}{\mathrm{~d} \gamma} \leq 0$ when $X(\gamma) \geq 0$, and $\frac{\mathrm{d} \phi_{0}}{\mathrm{~d} \gamma}>0$ when $X(\gamma)<0$; (2) $\frac{\mathrm{d} \phi_{1}}{\mathrm{~d} \gamma} \leq 0$ when $Y(\gamma) \geq 0$, and $\frac{\mathrm{d} \phi_{1}}{\mathrm{~d} \gamma}>0$ when $Y(\gamma)<0$.

Proof. See Appendix E.4.

Proposition 5.8 shows the impact of retailers' competition on the range of profit-sharing ratio $\phi$ that benefits both participators. From Lemma 5.5, $\phi_{0}$ is the positive root of equation $(\alpha-c)^{2}\left(4-\gamma^{2}\right)\left(1+\phi_{0}\right)^{2}-2(1+\gamma)[(2-$ $\left.\gamma)(\alpha-c)\left(\alpha-c-c I_{m}\right)+\left(c I_{m}\right)^{2}\right]\left(2+\phi_{0}\right)=0$. Thus, $\phi_{0}$ is related to $\gamma$. The inequality $X(\gamma) \geq 0$ implies a complex relationship of $\gamma$. Similarly, it is obscure to express $\gamma$ from equality $Y(\gamma)$, which implies $\pi_{M}^{V I}=\pi_{M}^{T C}$. Therefore, we use a set of numerical studies to show the effect of $\gamma$ on the evolution of the range of profit-sharing ratio $\phi$ that benefits both participators in Section 6 .

\subsection{Retailer $R_{2}$ 's profit under different settings}

In this subsection, we investigate how the manufacturer's choices of financing modes influence retailer $R_{2}$ 's profit. As for the retailer $R_{2}$, the comparisons of its order quantities and gainings in different cases are illustrated as follows.

Lemma 5.9. $q_{R_{2}}^{S^{*}}>q_{R_{2}}^{T C^{*}}>q_{R_{2}}^{V I^{*}}$.

Proof. See Appendix F.1.

Lemma 5.9 shows that if the manufacturer deselects retailer $R_{1}$ and only sells to retailer $R_{2}$, then $R_{2}$ has none competitor in the consumer market. Thus, the retailer $R_{2}$ makes the largest order quantity. If the manufacturer provides trade credit financing service to retailer $R_{1}$, retailer $R_{2}$ shares the market demand with $R_{1}$, and thus the horizontal competition between retailers reduces retailer $R_{2}$ 's order amount. If the manufacturer initiates a vertical merger strategy, the retailer $R_{2}$ competes with manufacturer for the consumer demand. This shows that the competition between two strong parties for terminal market is intensified, and thus the retailer $R_{2}$ will make the lowest order quantity.

Proposition 5.10. $\pi_{R_{2}}^{S}>\pi_{R_{2}}^{T C}>\pi_{R_{2}}^{V I}$.

Proof. See Appendix F.2.

Proposition 5.10 compares retailer $R_{2}$ 's profit under different cases. As a whole, deselecting retailer $R_{1}$ betters off than financing retailer $R_{1}$ for retailer $R_{2}$. If the manufacturer provides financial assistance to $R_{1}$, retailer $R_{2}$ prefers trade credit financing rather than vertical merger because the rival's competitive power is unfavorable for retailer $R_{2}$ 's order quantity, and thus reduces retailer $R_{2}$ 's profit. 


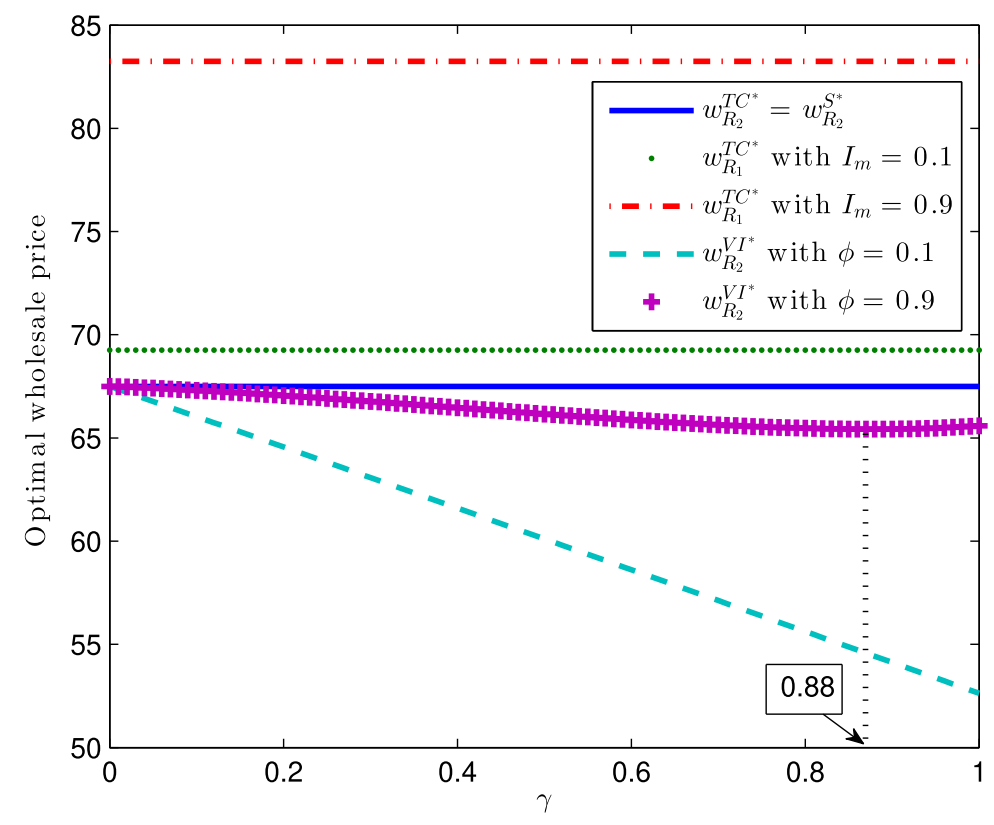

FIGURE 1. The impact of $\gamma$ on optimal wholesale price.

\section{NUMERICAL ANALYSIS}

In this section, we present some numerical examples to verify and extend our analysis in previous sections, and illustrate the impacts of competition intensity on manufacturer's pricing strategy and retailer's order decisions, as well as the payoffs for each participant and the whole supply chain under different settings. In addition, we exemplify the effect of competition on the evolution of the range of profit-sharing ratio $\phi$ that benefits both participators in vertical merger.

\subsection{The impact of competition intensity $\gamma$ on wholesale price}

We set exogenous variables as $\alpha=100, c=35, \beta=0.3, I_{m}=0.1$ (or 0.9 ) and $\phi=0.1$ (or 0.9 ) to show the impact of $\gamma$ on the manufacturer's optimal wholesale price for two retailers. Figure 1 illustrates that the wholesale price for retailer $R_{1}$ under trade credit is higher than that under other cases, which is consistent with Lemma 5.1. Under vertical merger, with increasing competition intensity $\gamma$, the wholesale price for retailer $R_{2}$ decreases if $\phi$ is not large (e.g., according to Corollary $4.7, \phi=0.1$ such that $\left.\left.\eta(\gamma)\right|_{\gamma \in[0,1]}>0\right)$. When $\phi$ is sufficiently large (e.g., $\phi=0.9), \eta(\gamma)$ will not always be positive in terms with $\gamma$. Figure 1 shows that the wholesale price firstly decreases with $\gamma \leq 0.88$ and then rises up with $\gamma>0.88$. Hence, the impact of $\gamma$ on the optimal wholesale price in Corollary 4.7 is exemplified.

\subsection{The impact of competition intensity $\gamma$ on order quantity}

We first show the retailer $R_{1}$ 's ordering decisions under two financing channels of trade credit and vertical merger. Figure 2 illustrates that retailer $R_{1}$ 's order quantity decreases with $\gamma$ under trade credit, which is shown in Corollary 4.3 as well. Vertical merger results in more sales volume for retailer $R_{1}$. And when $\phi$ is large $(e . g ., \phi=0.9)$, retailer $R_{1}$ 's sales quantity will first decrease with $\gamma(\gamma \leq 0.59)$ and then increase with $\gamma$ $(\gamma>0.59)$, which is shown in Corollary 4.7. Hence, when manufacturer shares more proportion of profit from merging retailer $R_{1}$, more intensified competition between two retailers results in a larger sales quantity under manufacturer's vertical merger, which partially verifies Corollary 4.8 . 


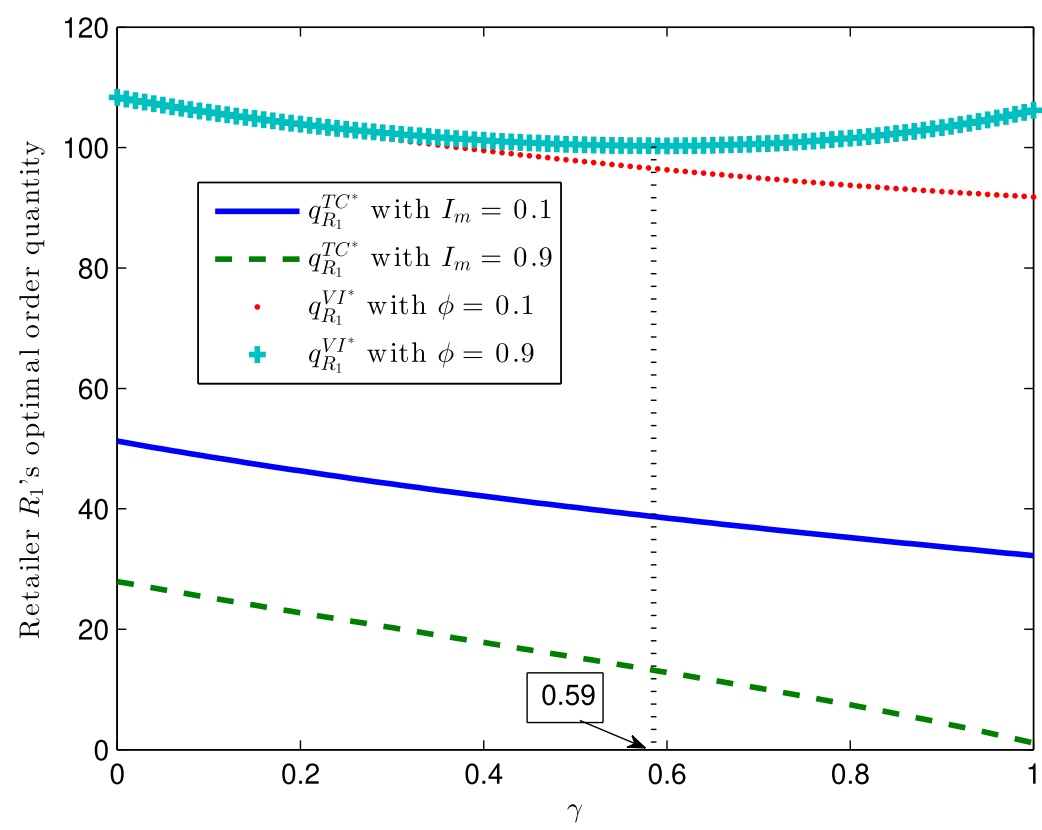

Figure 2. The impact of $\gamma$ on the retailer $R_{1}$ 's order quantity.

Figure 3 plots the impact of $\gamma$ on retailer $R_{2}$ 's optimal order quantity under different circumstances. We can observe that the competition in sales market mostly results in decreasing $R_{2}$ 's order quantity. However, with $I_{m} \geq 0.9$ in trade credit, if $\gamma>0.56$, its order quantity will increase with $\gamma$, which exemplifies the Corollary 4.3. Moreover, retailer $R_{2}$ makes the largest order quantity if manufacturer deselects retailer $R_{1}$, and the lowest order quantity under manufacturer's vertical merger, which is consistent with Lemma 5.9.

Figure 4 plots the comparisons of supply chain's order quantity under different cases. It shows that supply chain's whole order quantity decreases in terms with $\gamma$. Also, selling to two retailers promotes the whole order quantity of the supply chain, while trade credit is dominated by vertical merger for the whole supply chain's orders. Thus, Lemma 5.2 is verified.

\subsection{The impact of competition intensity $\gamma$ on profits}

We now compare each player's profit under trade credit and vertical merger respectively. We set $\alpha=100$, $c=35, \beta=0.3, I_{m}=0.1$ (or 0.9), $\phi=0.1$ (or 0.9 ) and $T=1500$. Figure 5 plots the impacts of $\gamma$ on manufacturer's payoffs under different channels. As a whole, manufacturer's profit decreases with competition intensity, and with a suitable $I_{m}$ in trade credit or $\phi$ in vertical merger, selling to two retailers can be more profitable than single distribution channel with retailer $R_{2}$. If $\gamma \leq 0.05$, vertical merger with a high $\phi(e . g$., $\phi=0.9)$ is the optimal choice for manufacturer. If $\gamma>0.05$, trade credit with a low $I_{m}\left(e . g ., I_{m}=0.1\right)$ will outperform other cases for manufacturer. Especially, if $\phi=I_{m}=0.9$, vertical merger is better off than trade credit with $\gamma \leq 0.85$, and oppositely, trade credit is more beneficial to manufacturer with $\gamma>0.85$. Meanwhile, if manufacturer shares few profit from vertical merger (e.g., $\phi=0.1$ ), he would like to choose to deselect or provide trade credit to retailer $R_{1}$, instead of merging retailer $R_{1}$. Hence, Figure 5 exemplified Proposition 5.3 and Lemma 5.6.

We plot the retailer $R_{1}$ 's profit under two financing types in Figure 6. We can observe that retailer's horizontal competition reduces retailer $R_{1}$ 's profit, except that under vertical merger with $\phi=0.9$. Figure 6 shows that if $\phi>\frac{2}{7}$ and $\gamma>\frac{4(1+\phi)-2 \sqrt{2 \phi(2 \phi+3)}}{2+\phi}=0.59$, retailer $R_{1}$ 's profit will slightly increases with $\gamma$, which is consistent 


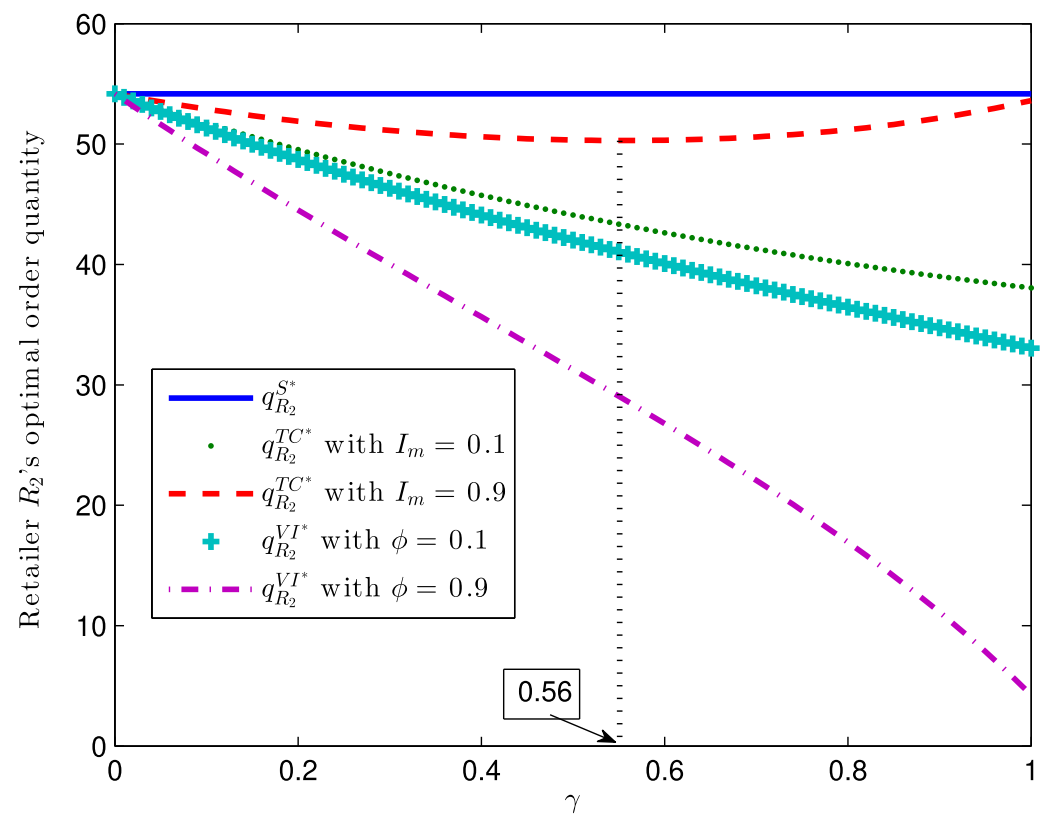

Figure 3. The impact of $\gamma$ on the retailer $R_{2}$ 's order quantity.

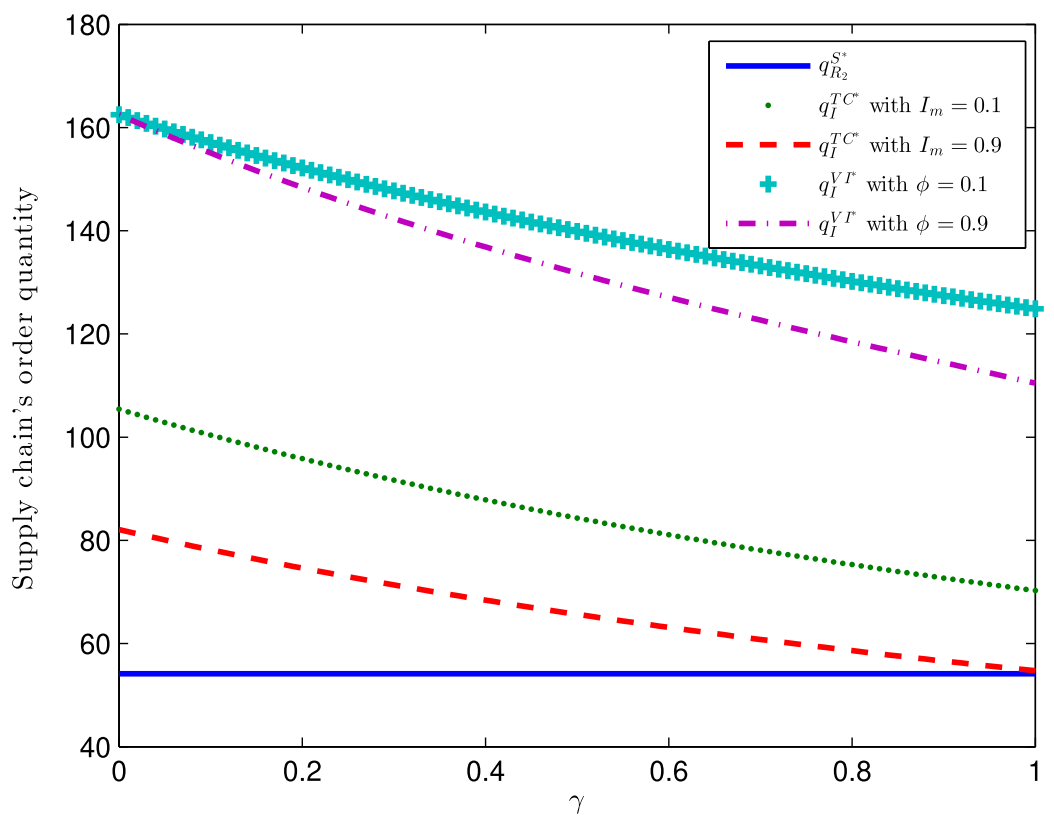

FIGURE 4. The impact of $\gamma$ on order quantity of the supply chain. 


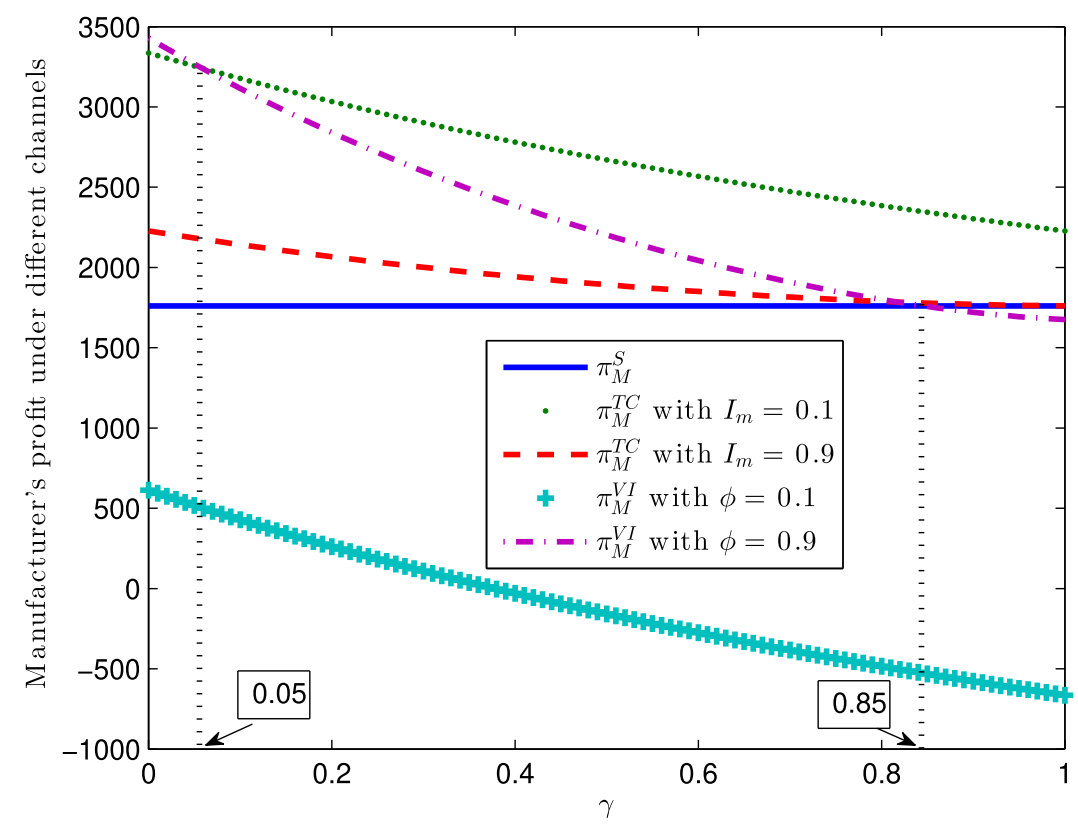

FIgURE 5. The impact of $\gamma$ on manufacturer's profit under different settings.

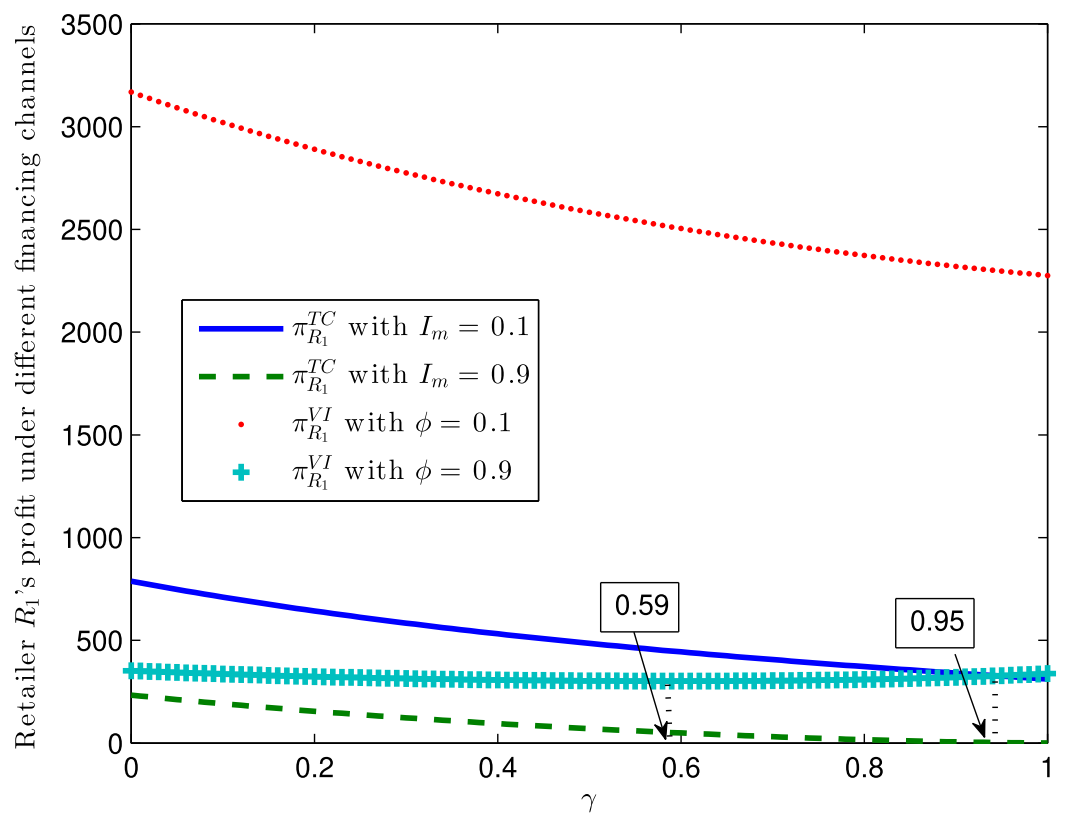

FIgURE 6 . The impact of $\gamma$ on retailer $R_{1}$ 's profit under different financing modes. 


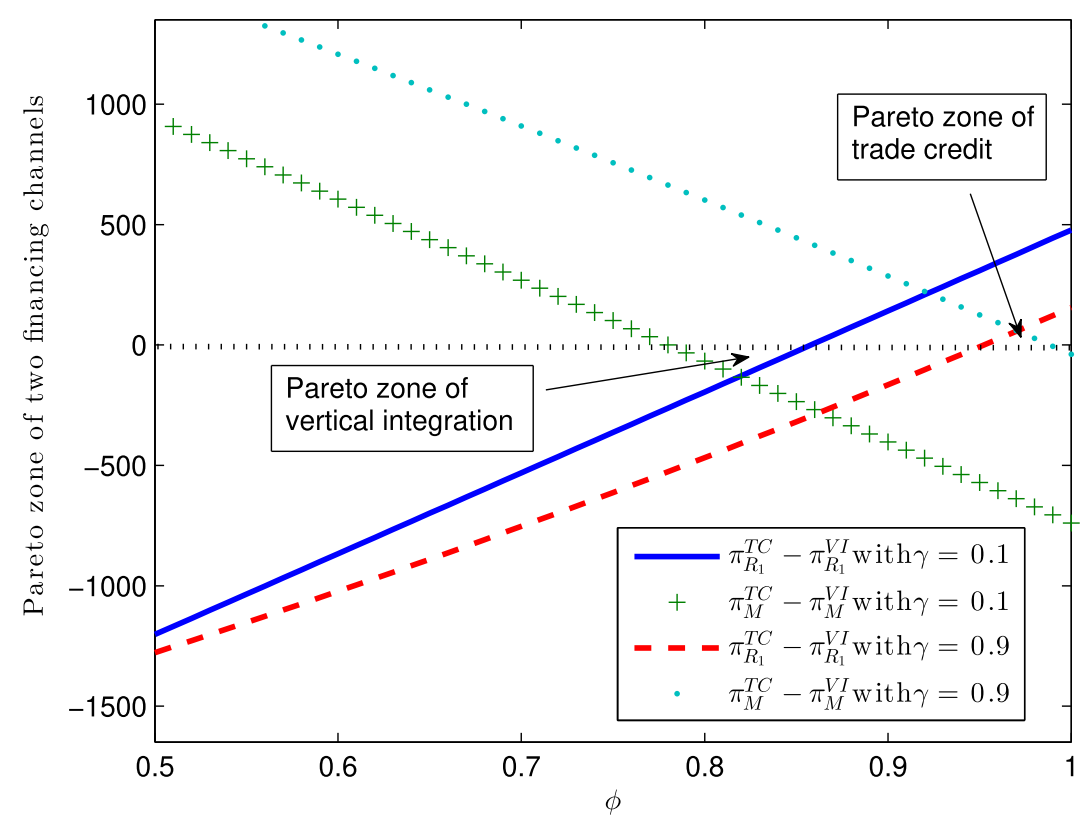

FiguRE 7. Profit differences between different financing contracts verse $\phi$ and $\gamma$.

with Corollary 4.7. Given $\phi=0.9$ in vertical merger and $I_{m}=0.1$ in trade credit, comparing with two financing contracts, when $\gamma \leq 0.95$, trade credit contract creates more profit for retailer $R_{1}$, and when $\gamma>0.95$, although retailer $R_{1}$ shares little profit with a ratio of $1-\phi=0.1$, vertical merger outperforms trade credit. Because according to Corollary 4.6 and Corollary 4.7, under vertical merger, a high $\phi$ and $\gamma$ will result in a large market sales quantity for retailer $R_{1}$ in direct sales channel, although $R_{1}$ 's profit-sharing percentage is relatively low, the large sales amount can make vertical merger be beneficial for retailer $R_{1}$. Thus, the relationship between retailer $R_{1}$ 's profit and $\gamma$, which is separately shown in Corollary 4.4, Corollary 4.7, and Lemma 5.5, is verified.

Setting $\alpha=100, c=35, \beta=0.3, I_{m}=0.4, \gamma=0.1$ (or 0.9 ) and $T=1500$, we compare the profits of manufacturer and retailer $R_{1}$ and show the ranges of $\phi$ that benefit to both participators of two financing modes separately. When the horizontal competition between retailers is not so intensified $(e . g ., \gamma=0.1)$, if manufacturer shares a profit with ratio $\phi \in[0.78,0.86]$ in direct sales channel, the vertical merger outperforms trade credit for both manufacturer and retailer $R_{1}$. However, with the competition becomes increasingly fierce (e.g., $\gamma=0.9)$, if $\phi$ is between [0.95,0.99], trade credit dominates vertical merger for both parties. In other words, under intensified competitive sales market, considering both parties' profits in the financing contract, the superiority of trade credit is significant only when manufacturer shares almost all of the profits from vertical acquisition of retailer $R_{1}$. Given a moderate capital cost and fierce competition (e.g., $\left.I_{m}=0.4, \gamma=0.9\right)$, manufacturer's profit under trade credit is larger than that under vertical merger, while as for retailer $R_{1}$, as long with a very low profit-sharing percentage (i.e., $1-\phi<0.05)$ in direct sales channel, trade credit dominates vertical merger. Hence, Figure 7 exemplifies the results shown in Proposition 5.7.

Furthermore, we explore the impact of $\gamma$ and $I_{m}$ on the range of profit-sharing ratio $\phi$ under which trade credit or vertical merger can be better for both manufacturer and retailer $R_{1}$ in Table 2 . Table 2 shows that if $I_{m}$ is not large (i.e., $I_{m}<0.7$ ), there exists a range of $\phi$ that trade credit outperforms vertical merger for two parties. With the increased $I_{m}$, the strength of trade credit becomes less significant, and vertical merger prevails over trade credit when $I_{m} \geq 0.7$. Note that, given a $I_{m}$, the range of $\phi$ that benefits either for trade credit or vertical merger is more and more narrow with the increased $\gamma$. Given a certain value of $\gamma$, the range for vertical merger is extended with the increased $I_{m}$, and becomes more narrow with $I_{m}$ under trade credit. 
TABLE 2. The impact of $\gamma$ and $I_{m}$ on the range of $[\phi, \bar{\phi}]$ under vertical integration or trade credit.

\begin{tabular}{cccccc}
\hline \hline \multirow{2}{*}{$I_{m}$} & \multicolumn{5}{c}{$\gamma$} \\
\cline { 2 - 6 } & 0.1 & 0.3 & 0.5 & 0.7 & 0.9 \\
\hline 0.1 & {$[0.79,0.91]$} & {$[0.82,0.99]$} & {$[0.84,1.00]$} & {$[0.87,1.00]$} & {$[0.90,1.00]$} \\
0.3 & {$[0.83,0.84]$} & {$[0.87,0.90]$} & {$[0.89,0.96]$} & {$[0.92,1.00]$} & {$[0.94,1.00]$} \\
0.5 & {$[0.75,0.87]$} & {$[0.83,0.90]$} & {$[0.90,0.92]$} & {$[0.96,0.96]$} & {$[0.97,0.97]$} \\
0.7 & {$[0.67,0.91]$} & {$[0.77,0.93]$} & {$[0.85,0.95]$} & {$[0.91,0.97]$} & {$[0.94,0.98]$} \\
0.9 & {$[0.62,0.94]$} & {$[0.71,0.96]$} & {$[0.80,0.97]$} & {$[0.87,0.98]$} & {$[0.92,0.99]$} \\
\hline
\end{tabular}

Note. The regular script number represents the range for vertical merger, and the italic number represents the range for trade credit.

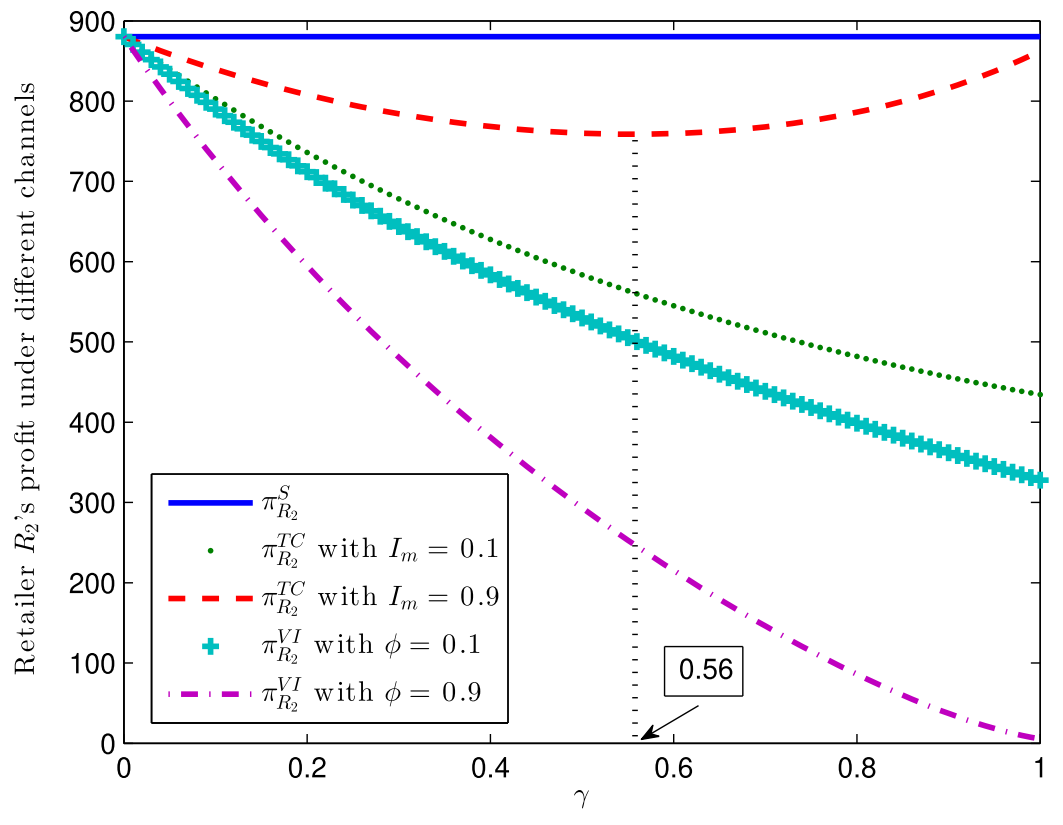

FiguRE 8 . The impact of $\gamma$ on retailer $R_{2}$ 's profit under different channels.

Therefore, the horizontal competition in sales market will weaken the effect of both financing channels. As a Pareto player, the manufacturer should concern the profits of both lenders and borrowers. If manufacturer's capital cost $I_{m}$ is not so high, trade credit can be the best choice to finance the capital constrained retailer. If $I_{m}$ is relatively high, and the administrative cost due to merger and acquisition is less than some extent, vertical merger contract with a reasonable profit-sharing ratio will outperform the trade credit. Therefore, the Proposition 5.8 is numerically verified.

Finally, as far as retailer $R_{2}$ is concerned, we examine the retailer $R_{2}$ 's profit and supply chain's profit with $\gamma$ under different settings. From Figure 8, we can find that because retailer $R_{2}$ has sufficient money to pay the purchase, manufacturer's deselecting $R_{1}$ is much more beneficial than financing $R_{1}$ for retailer $R_{2}$. While if manufacturer decides to finance retailer $R_{1}$, then trade credit brings more profit for $R_{2}$ than vertical merger. Moreover, retailer $R_{2}$ 's profit decreases with competition intensity $\gamma$ except that under trade credit with a high $I_{m}$. For example, if manufacturer's capital cost $I_{m}=0.9$, retailer $R_{2}$ 's earning decreases with $\gamma<0.56$ while increasing with $\gamma \geq 0.56$ under trade credit. This is because a high capital cost will result in a higher wholesale price and lower order quantity for retailer $R_{1}$. This implies that retailer $R_{2}$ can share more market demand, and 


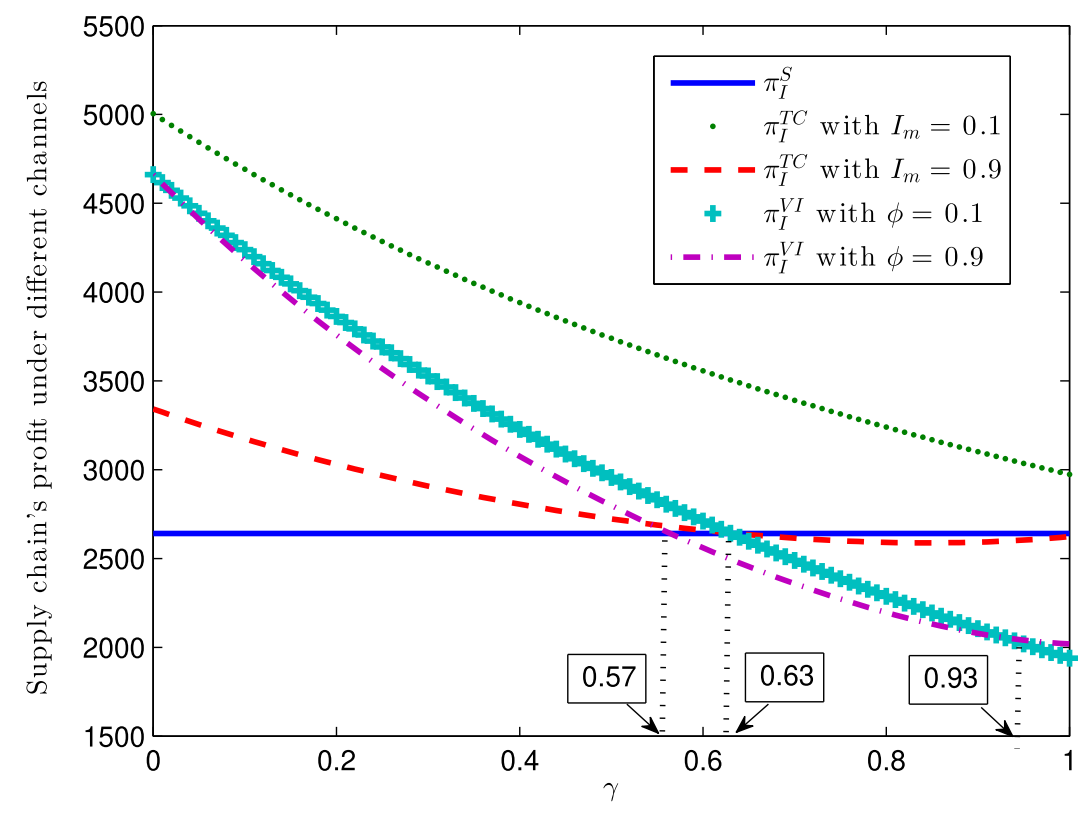

FIGURE 9. The impact of $\gamma$ on supply chain's profit under different channels.

more intensified competition induces $R_{2}$ to aggressively struggle for more sales. Thus, the retailer $R_{2}$ 's profit is convex with $\gamma$. The findings from Figure 8 are consistent with the Corollary 4.4 and Proposition 5.10.

In addition, Figure 9 characterizes the effect of $\gamma$ on the profit of whole supply chain, which includes two retailers and a manufacturer. Because there is no competition for two retailers in sales market if retailer $R_{1}$ is deselected, supply chain's profit has no correlation with $\gamma$. With $I_{m}=0.1$, the supply chain's profit under trade credit is significantly larger than that under other cases. While given $I_{m}=0.9$ in trade credit and $\phi=0.9$ in vertical merger contract, when $\gamma \leq 0.57$, vertical merger brings the largest profit for supply chain, while when $\gamma>0.57$, deselecting retailer $R_{1}$ can be the optimal choice to maximize the whole profit of supply chain. Also, if $\phi=0.1$, vertical merger betters off than other cases with $\gamma \leq 0.63$, and when $\gamma>0.63$, single distribution channel with retailer $R_{2}$ is the optimal choice for supply chain's profit. Meanwhile, Figure 9 shows that when $\gamma \leq 0.93$, increasing $\phi$ will lead to a lower profit for the whole supply chain, while if $\gamma>0.93$, a large $\phi$ will result in more profits for supply chain. As a whole, with the increased horizontal competition intensity, the financing channel of trade credit with suitable $I_{m}$ can be beneficial for supply chain.

\section{Conclusions And FUture EXtensions}

In this paper, we study the manufacturer's decisions of financing choice (i.e., trade credit versus vertical merger with a capital-constrained retailer) in a one-manufacturer-two-retailers supply chain, in which one of these retailers has limited capitals to procure, and competes with a fund-abundant retailer for sales market in Cournot competition mode. We investigate the two retailers' equilibrium ordering and manufacturer's pricing decisions in different distribution and financing options. In addition, we examined the impact of retailers' competition intensity on the manufacturer's decision on financing strategies.

The results in our study show that for the wholesale price, the manufacturer sets the highest price for capitalconstrained retailer under trade credit and the lowest price for fund-abundant retailer under vertical merger. In vertical merger, if the manufacturer's profit-sharing proportion is larger than a certain threshold, with the increased competition between two retailers, the higher wholesale price should be set for fund-abundant retailer. 
For the order quantity, we find that the fund-abundant retailer makes the largest ordering if manufacturer deselects the capital-constrained retailer, and the capital-constrained retailer makes the largest order quantity in the vertical merger. In addition, we find that manufacturer's selling to two retailers improves the whole supply chain's order quantity.

In addition, our study shows that if the capital cost or acquisition fee is relatively low, the manufacturer would like to finance the capital-constrained retailer. Given a fixed acquisition fee, when the capital cost is below to certain level, trade credit outperforms vertical merger with an appropriate dividend sharing ratio, which is optimal for both parties in the financing contract. If the capital cost is higher than a certain threshold, vertical merger betters off than trade credit. However, the horizontal competition of two retailers weakens the effect of both financing modes on each party's profit in the financing contract. Moreover, our paper also shows that the fund-abundant retailer obtain the highest profits if manufacturer deselects capital-constrained retailer and lowest under vertical merger. Our study provides a roadmap for the manufacturer to choose the optimal financing options to maximize the profits when facing competition between retailers with financial constraints.

Our study can be extended through the following aspects. First, we used a linear deterministic function to characterize product price and demand. The trade credit financing and merger strategy under stochastic demand can be studied in the future. Second, we considered that one retailer has capital constraints in this study. Future studies can examine that if both retailers have limited fund to procure, how the manufacturer offers financing service and how to perform a merger. Third, our model can be extended to include multiple heterogeneous retailers (e.g., a dominant retailer leading the sales market and several follower retailers), asymmetric information in supply chain, or other financing channels (e.g., bank financing, factoring, etc.).

\section{Appendix A. Proof of Proposition 4.1}

Because $\frac{\mathrm{d}^{2} \pi_{R_{2}}^{S}}{\mathrm{~d}\left(q_{R_{2}}^{S}\right)^{2}}=-2 \beta$, the first order condition of equation (4.1) indicates that $q_{R_{2}}^{S_{2}^{*}}=\frac{\alpha-w_{R_{2}}^{S}}{2 \beta}$. Substituting this into equation (4.2), we have $\frac{\mathrm{d}^{2} \pi_{M}^{S}}{\mathrm{~d}\left(w_{R_{2}}^{S}\right)^{2}}=-\frac{1}{\beta}$, and the first order condition of equation (4.2) indicates that the optimal wholesale price is $w_{R_{2}}^{S^{*}}=\frac{\alpha+c}{2}$. Thus, the retailer $R_{2}$ 's optimal order quantity is $q_{R_{2}}^{S^{*}}=\frac{\alpha-c}{4 \beta}$, and each member's profit is $\pi_{R_{2}}^{S}=\frac{(\alpha-c)^{2}}{16 \beta}, \pi_{M}^{S}=\frac{(\alpha-c)^{2}}{8 \beta}$.

\section{ApPEndix B.}

\section{B.1. Proof of Proposition 4.2}

With backward induction approach, we first solve the retailers' equilibrium ordering decisions from the first order condition of equations (4.3) and (4.4) as follows:

$$
\begin{aligned}
q_{R_{1}}^{T C^{*}} & =\frac{(2-\gamma) \alpha-2 w_{R_{1}}^{T C}+w_{R_{2}}^{T C} \gamma}{\beta\left(4-\gamma^{2}\right)}, \\
q_{R_{2}}^{T C^{*}} & =\frac{(2-\gamma) \alpha+2 w_{R_{2}}^{T C}+w_{R_{1}}^{T C} \gamma}{\beta\left(4-\gamma^{2}\right)} .
\end{aligned}
$$

Plug $q_{R_{1}}^{T C^{*}}$ and $q_{R_{2}}^{T C^{*}}$ into equation (4.5), and take the derivation of $\pi_{M}^{T C}$ with $w_{R_{1}}^{T C}$ and $w_{R_{2}}^{T C}$ separately, we have

$$
\left\{\begin{array}{l}
\frac{\partial \pi_{M}^{T C}}{\partial w_{R_{1}}^{T C}}=\frac{(2-\gamma)(\alpha+c)+2 c\left(1+I_{m}\right)-4 w_{R_{1}}^{T C}+2 \gamma w_{R_{2}}^{T C}}{\beta\left(4-\gamma^{2}\right)} \\
\frac{\partial \pi_{M}^{T C}}{\partial w_{R_{2}}^{T C}}=\frac{(2-\gamma)(\alpha+c)-c I_{m} \gamma-4 w_{R_{2}}^{T C}+2 \gamma w_{R_{1}}^{T C}}{\beta\left(4-\gamma^{2}\right)} .
\end{array}\right.
$$


From the above equation, we have the manufacturer's optimal pricing decision as $w_{R_{1}}^{T C^{*}}=\frac{\alpha+c\left(1+I_{m}\right)}{2}, w_{R_{2}}^{T C^{*}}=$ $\frac{\alpha+c}{2}$. Therefore the retailers' equilibrium order quantities are $q_{R_{1}}^{T C^{*}}=\frac{(2-\gamma)(\alpha-c)-2 c I_{m}}{2 \beta\left(4-\gamma^{2}\right)}, q_{R_{2}}^{T C^{*}}=\frac{(2-\gamma)(\alpha-c)+\gamma c I_{m}}{2 \beta\left(4-\gamma^{2}\right)}$. Thus, each player's profit is $\pi_{R_{1}}^{T C}=\beta\left(q_{R_{1}}^{T C^{*}}\right)^{2}, \pi_{R_{2}}^{T C}=\beta\left(q_{R_{2}}^{T C^{*}}\right)^{2}, \pi_{M}^{T C}=\frac{(2-\gamma)(\alpha-c)\left(\alpha-c-c I_{m}\right)+\left(c I_{m}\right)^{2}}{2 \beta\left(4-\gamma^{2}\right)}$.

\section{B.2. Proof of Corollary 4.3}

(1) $\frac{\mathrm{d} q_{R_{1}}^{T C^{*}}}{\mathrm{~d} \gamma}=-\frac{c I_{m}}{4 \beta(2-\gamma)^{2}}-\frac{2(\alpha-c)-c I_{m}}{4 \beta(2+\gamma)^{2}}<0$;

(2) $\frac{\mathrm{d} q_{R_{2}}^{T C^{*}}}{\mathrm{~d} \gamma}=\frac{c I_{m}}{4 \beta(2-\gamma)^{2}}-\frac{2(\alpha-c)-c I_{m}}{4 \beta(2+\gamma)^{2}}$, and $\frac{\mathrm{d}^{2} q_{R_{2}}^{T C^{*}}}{\mathrm{~d} \gamma^{2}}=\frac{c I_{m}}{2 \beta(2-\gamma)^{3}}+\frac{2(\alpha-c)-c I_{m}}{2 \beta(2+\gamma)^{3}}>0$. Therefore, if $I_{m}<\frac{\alpha-c}{5 c}$, then $\frac{2\left[\alpha-c-\sqrt{c I_{m}\left(2(\alpha-c)-c I_{m}\right)}\right]}{\alpha-c-c I_{m}}>1$, and thus $q_{R_{2}}^{T C^{*}}$ decreases with $\gamma \in[0,1]$. While if $I_{m} \geq \frac{\alpha-c}{5 c}$, then $0<$ $\frac{2\left[\alpha-c-\sqrt{c I_{m}\left(2(\alpha-c)-c I_{m}\right)}\right]}{\alpha-c-c I_{m}}<1$, and thus $q_{R_{2}}^{T C^{*}}$ decreases with $\gamma$ when $\gamma \in\left[0, \frac{2\left[\alpha-c-\sqrt{c I_{m}\left(2(\alpha-c)-c I_{m}\right)}\right]}{\alpha-c-c I_{m}}\right]$ and increases with $\gamma$ when $\gamma \in\left[\frac{2\left[\alpha-c-\sqrt{c I_{m}\left(2(\alpha-c)-c I_{m}\right)}\right]}{\alpha-c-c I_{m}}, 1\right]$.

(3) $\frac{\mathrm{d}\left(q_{R_{1}}^{T C^{*}}+q_{R_{2}}^{T C^{*}}\right)}{\mathrm{d} \gamma}=-\frac{2(\alpha-c)-c I_{m}}{2 \beta(2+\gamma)^{2}}$ due to $\alpha-c-c I_{m}>0$, and thus $\frac{\mathrm{d}\left(q_{R_{1}}^{T C^{*}}+q_{R_{2}}^{T C^{*}}\right)}{\mathrm{d} \gamma}<0$.

\section{B.3. Proof of Corollary 4.4}

From Proposition $4.2, \frac{\mathrm{d} \pi_{R_{1}}^{T C}}{\mathrm{~d} \gamma}=2 \beta q_{R_{1}}^{T C^{*}} \frac{\mathrm{d} q_{R_{1}}^{T C^{*}}}{\mathrm{~d} \gamma}$, and $\frac{\mathrm{d} \pi_{R_{2}}^{T C}}{\mathrm{~d} \gamma}=2 \beta q_{R_{2}}^{T C^{*}} \frac{\mathrm{d} q_{R_{2}}^{T C^{*}}}{\mathrm{~d} \gamma}$. Thus, $\frac{\mathrm{d} \pi_{R_{i}}^{T C}}{\mathrm{~d} \gamma}(i=1,2)$ has the same tendency with $\frac{\mathrm{d} q_{R_{i}}^{T C^{*}}}{\mathrm{~d} \gamma}(i=1,2) . \frac{\mathrm{d} \pi_{M}^{T C}}{\mathrm{~d} \gamma}=-\frac{\left[(\alpha-c)(2-\gamma)-2 c I_{m}\right]\left[(\alpha-c)(2-\gamma)+c I_{m} \gamma\right]}{2 \beta\left(4-\gamma^{2}\right)^{2}}<0$.

\section{Appendix C.}

\section{C.1. Proof of Proposition 4.5}

(1) The retailers' equilibrium order quantities are derived from $\frac{\mathrm{d} \pi_{R_{2}}^{V I}}{\mathrm{~d} q_{R_{2}}^{V I}}=0$ and $\frac{\mathrm{d} \pi_{M}^{V I}}{\mathrm{~d} q_{R_{1}}^{V I}}=0$, which implies that $q_{R_{1}}^{V I^{*}}=\frac{2(\alpha-c)-\left(\alpha-w_{R_{2}}^{V I}\right) \gamma}{\beta\left(4-\gamma^{2}\right)}$, and $q_{R_{2}}^{V I^{*}}=\frac{2\left(\alpha-w_{R_{2}}^{T C}\right)-(\alpha-c) \gamma}{\beta\left(4-\gamma^{2}\right)}$. Plug $q_{R_{i}}^{V I^{*}}(i=1,2)$ into manufacturer's profit as equation (4.7), we have $\frac{\mathrm{d}^{2} \pi_{M}^{V I}}{\mathrm{~d}\left(w_{R_{2}}^{V I}\right)^{2}}=\frac{-16+2 \gamma^{2}(2+\phi)}{\beta\left(4-\gamma^{2}\right)^{2}}$. Due to $\gamma \in[0,1]$ and $\phi \in[0,1], \frac{\mathrm{d}^{2} \pi_{M}^{V I}}{\mathrm{~d}\left(w_{R_{2}}^{V I}\right)^{2}}<0$, and thus manufacturer's pricing decision is derived from $\frac{\mathrm{d} \pi_{M}^{V I}}{\mathrm{~d} w_{R_{2}}^{V I}}=0$. That is, $w_{R_{2}}^{V I^{*}}=\frac{\left(4-\gamma^{2}\right)[2(\alpha+c)-\gamma(\alpha-c)]+2 \gamma \phi[2(\alpha-c)-\alpha \gamma]}{2\left[8-\gamma^{2}(2+\phi)\right]}$.

(2) Substitute $w_{R_{2}}^{V I^{*}}$ into $q_{R_{i}}^{V I^{*}}(i=1,2), q_{R_{1}}^{V I^{*}}$ can be rewritten as $q_{R_{1}}^{V I^{*}}=\frac{(\alpha-c)(2-\gamma)(4+\gamma)}{2 \beta\left[8-\gamma^{2}(2+\phi)\right]}$ and $q_{R_{2}}^{V I^{*}}=$ $\frac{(\alpha-c)[2-\gamma(1+\phi)]}{\beta\left[8-\gamma^{2}(2+\phi)\right]}$.

(3) Substitute $w_{R_{2}}^{V I^{*}}, q_{R_{i}}^{V I^{*}}(i=1,2)$ into equations (4.6)-(4.8) separately, we have $\pi_{R_{1}}^{V I}=(1-\phi) \beta\left(q_{R_{1}}^{V I^{*}}\right)^{2}, \pi_{R_{2}}^{V I}=$ $\beta\left(q_{R_{2}}^{V I^{*}}\right)^{2}$, and $\pi_{M}^{V I}=\frac{(\alpha-c)^{2}(2-\gamma)(2-\gamma+4 \phi)}{4 \beta\left[8-\gamma^{2}(2+\phi)\right]}-T$.

\section{C.2. Proof of Corollary 4.6}

(1) $\frac{\partial w_{R_{2}}^{V I^{*}}}{\partial \phi}=-\frac{(\alpha-c) \gamma(2-\gamma)^{2}(2+\gamma)(4+\gamma)}{2\left(8-\gamma^{2}(2+\phi)\right)^{2}}>0$;

(2) $\frac{\partial q_{R_{1}}^{V I^{*}}}{\partial \phi}=\frac{(\alpha-c)(2-\gamma) \gamma^{2}(4+\gamma)}{2 \beta\left(8-\gamma^{2}(2+\phi)\right)^{2}}>0, \frac{\partial q_{R_{2}}^{V I^{*}}}{\partial \phi}=-\frac{(\alpha-c)(2-\gamma) \gamma(4+\gamma)}{\beta\left(8-\gamma^{2}(2+\phi)\right)^{2}}<0$;

(3) $\frac{\partial \pi_{R_{1}}^{V I}}{\partial \phi}=-\frac{(\alpha-c)^{2}(2-\gamma)^{2}(4+\gamma)^{2}\left(8-\gamma^{2}(4-\phi)\right)}{4 \beta\left(8-\gamma^{2}(2+\phi)\right)^{3}}<0, \frac{\partial \pi_{R_{2}}^{V I}}{\partial \phi}=-(2-\gamma) \gamma(4+\gamma) \frac{2(\alpha-c)^{2}(2-\gamma(1+\phi))}{\beta\left(8-\gamma^{2}(2+\phi)\right)^{3}}<0, \frac{\partial \pi_{M I}^{V I}}{\partial \phi}=$ $\frac{(\alpha-c)^{2}(2-\gamma)^{2}(4+\gamma)^{2}}{4 \beta\left(8-\gamma^{2}(2+\phi)\right)^{2}}>0$. 


\section{C.3. Proof of Corollary 4.7}

(1) $\frac{\partial w_{R_{2}}^{V I^{*}}}{\partial \gamma}=-\eta(\gamma) \frac{\alpha-c}{2\left(8-\gamma^{2}(2+\phi)\right)^{2}}$. And thus given a $\phi$, if $\eta(\gamma)>0$, then $\frac{\partial w_{R_{2}}^{V I^{*}}}{\partial \gamma}<0$.

(2) $\frac{\partial q_{R_{1}}^{V I^{*}}}{\partial \gamma}=-\frac{(\alpha-c)\left[8-8 \gamma(1+\phi)+\gamma^{2}(2+\phi)\right]}{\beta\left(8-\gamma^{2}(2+\phi)\right)^{2}}$. Thus, $\frac{\partial q_{R_{1}}^{V I^{*}}}{\partial \gamma} \geq 0 \Leftrightarrow 8-8 \gamma(1+\phi)+\gamma^{2}(2+\phi) \leq 0$. Solving the inequality $8-8 \gamma(1+\phi)+\gamma^{2}(2+\phi) \leq 0$ and combining with $\gamma \in[0,1]$, we have $\gamma \in\left[\frac{4(1+\phi)-2 \sqrt{2 \phi(2 \phi+3)}}{2+\phi}, 1\right]$. Because $\frac{4(1+\phi)-2 \sqrt{2 \phi(2 \phi+3)}}{2+\phi}>0$, the condition that $\frac{4(1+\phi)-2 \sqrt{2 \phi(2 \phi+3)}}{2+\phi}<1$ implies that $\phi \geq \frac{2}{7}$. Thus, $\frac{\partial q_{R_{1}}^{V I *}}{\partial \gamma} \geq 0$ only if $\frac{2}{7} \leq \phi \leq 1$ and $\gamma \in\left[\frac{4(1+\phi)-2 \sqrt{2 \phi(2 \phi+3)}}{2+\phi}, 1\right]$; otherwise, $\frac{\partial q_{R_{1}}^{V I *}}{\partial \gamma}<0$. $\frac{\partial q_{R_{2}}^{V I^{*}}}{\partial \gamma}=$ $-\frac{(\alpha-c)[8(1+\phi)-\gamma(2+\phi)(4-\gamma(1+\phi))]}{\beta\left(8-\gamma^{2}(2+\phi)\right)^{2}}$. Because $[8(1+\phi)-\gamma(2+\phi)(4-\gamma(1+\phi))]_{\gamma}^{\prime}=(2+\phi)[-4+2 \gamma(1+\phi)] \leq 0$, and then $[8(1+\phi)-\gamma(2+\phi)(4-\gamma(1+\phi))] \geq\left.[8(1+\phi)-\gamma(2+\phi)(4-\gamma(1+\phi))]\right|_{\gamma=1}=2+7 \phi+\phi^{2}>0$, and $\frac{\partial q_{R_{2}}^{V I^{*}}}{\partial \gamma}<0$.

(3) From Proposition 4.5 , we can see that $\frac{\partial \pi_{R_{i}}^{V I}}{\partial \gamma}$ has the identical tendency with $\frac{\partial q_{R_{i}}^{V I^{*}}}{\partial \gamma}$. $\frac{\partial \pi_{M I}^{V I}}{\partial \gamma}=-(\alpha-$ $c)^{2} \frac{[2-\gamma(1+\phi)][4(1+\phi)-\gamma(2+\phi)]}{\beta\left(8-\gamma^{2}(2+\phi)\right)^{2}}<0$.

\section{C.4. Proof of Corollary 4.8}

$$
\begin{aligned}
& q_{R_{1}}^{V I^{*}}-q_{R_{2}}^{V I^{*}}=\frac{(\alpha-c)\left(4-\gamma^{2}+2 \gamma \phi\right)}{2 \beta\left(8-\gamma^{2}(2+\phi)\right)}>0, \frac{\partial\left(q_{R_{1}}^{V I^{*}}-q_{R_{2}}^{V I^{*}}\right)}{\partial \phi}=\gamma(2+\gamma)(4+\gamma) \frac{(\alpha-c)(2-\gamma)}{2 \beta\left(8-\gamma^{2}(2+\phi)\right)^{2}}>0, \text { and } \frac{\partial\left(q_{R_{1}}^{V I^{*}}-q_{R_{2}}^{V I^{*}}\right)}{\partial \gamma}= \\
& (\alpha-c) \phi \frac{8+\gamma(4+\gamma(2+\phi))}{\beta\left(8-\gamma^{2}(2+\phi)\right)^{2}}>0 .
\end{aligned}
$$

\section{C.5. Proof of Corollary 4.9}

In accordance with Corollary 4.8 and equation (3.1), $p_{R_{1}}^{V I^{*}}-p_{R_{2}}^{V I^{*}}=-\frac{(\alpha-c)(1-\gamma)\left(4-\gamma^{2}+2 \gamma \phi\right)}{2\left(8-\gamma^{2}(2+\phi)\right)}<0$, and $\frac{\partial\left(p_{R_{1}}^{V^{*}}-p_{R_{2}}^{V I^{*}}\right)}{\partial \phi}=-\gamma \frac{(\alpha-c)\left(4-\gamma^{2}\right)(1-\gamma)(4+\gamma)}{2\left(8-\gamma^{2}(2+\phi)\right)^{2}}<0 . \frac{\partial\left(p_{R_{1}}^{V I^{*}}-p_{R_{2}}^{V I^{*}}\right)}{\partial \gamma}=\frac{\alpha-c}{2\left(8-\gamma^{2}(2+\phi)\right)^{2}}\left[16(2-\phi)+24 \gamma \phi+\gamma^{4}(2+\phi)-\right.$ $\left.2 \gamma^{2}\left(8+\phi^{2}\right)\right]$. Due to $16(2-\phi)+24 \gamma \phi+\gamma^{4}(2+\phi)-2 \gamma^{2}\left(8+\phi^{2}\right)=16\left(2-\phi-\gamma^{2}\right)+2 \gamma \phi(12-\gamma \phi)+\gamma^{4}(2+\phi)>0$, $\frac{\partial\left(p_{R_{1}}^{V I^{*}}-p_{R_{2}}^{V I^{*}}\right)}{\partial \gamma}>0$.

\section{Appendix D.}

\section{D.1. Proof of Lemma 5.1}

From Proposition 4.1 and Proposition 4.2, we have $w_{R_{1}}^{T C^{*}}>w_{R_{2}}^{T C^{*}}=w_{R_{2}}^{S^{*}}$. Corollary 4.6 shows that $w_{R_{2}}^{V I^{*}}$ increases with $\phi$, and thus $w_{R_{2}}^{V I^{*}} \leq\left. w_{R_{2}}^{V I^{*}}\right|_{\phi=1}=\frac{\left(4-\gamma^{2}\right)[2(\alpha+c)-\gamma(\alpha-c)]+2 \gamma[2(\alpha-c)-\alpha \gamma]}{2\left(8-3 \gamma^{2}\right)}$. Due to $0<\gamma<1$, $\frac{\left(4-\gamma^{2}\right)[2(\alpha+c)-\gamma(\alpha-c)]+2 \gamma[2(\alpha-c)-\alpha \gamma]}{2\left(8-3 \gamma^{2}\right)}<\frac{\alpha+c}{2}$, we have $w_{R_{1}}^{T C^{*}}>w_{R_{2}}^{T C^{*}}=w_{R_{2}}^{S^{*}}>w_{R_{2}}^{V I^{*}}$.

\section{D.2. Proof of Lemma $\mathbf{5 . 2}$}

$$
q_{I}^{T C^{*}}=\frac{2(\alpha-c)-c I_{m}}{2 \beta(2+\gamma)}, q_{I}^{V I^{*}}=\frac{(\alpha-c)\left(12-4 \gamma-\gamma^{2}-2 \gamma \phi\right)}{2 \beta\left[8-\gamma^{2}(2+\phi)\right]} \text {. Because }-c I_{m}\left[8-\gamma^{2}(2+\phi)\right]<0<8-\gamma(\gamma+1)^{2}+\gamma(5-4 \phi),
$$
$q_{I}^{T C^{*}}<q_{I}^{V I^{*}}$. Proposition 4.2 shows $q_{R_{1}}^{T C^{*}}>0$, which implies that $(2-\gamma)(\alpha-c)-2 c I_{m}>0$, and thus $q_{R_{2}}^{S^{*}}<q_{I}^{T C^{*}}<q_{I}^{V I^{*}}$.

\section{D.3. Proof of Proposition 5.3}

Comparing manufacturer's profit under single channel in Proposition 4.1, under trade credit in Proposition 4.2 and under vertical merger in Proposition 4.5, we have if $I_{m}<\frac{(2-\gamma)(\alpha-c)}{2 c}$, then $\pi_{M}^{T C}>\pi_{M}^{S}$; and if $0<T<$ $\frac{\phi(4-\gamma)^{2}-4 \gamma(2-\gamma)}{8 \beta\left[8-\gamma^{2}(2+\phi)\right]}$, then $\pi_{M}^{V I}>\pi_{M}^{S}$. 


\section{D.4. Proof of Corollary 5.4}

From Proposition 5.3, we have $\frac{\mathrm{d} \frac{\phi(4-\gamma)^{2}-4 \gamma(2-\gamma)}{8 \beta\left[8-\gamma^{2}(2+\phi)\right]}}{\mathrm{d} \gamma}=-\frac{[2-\gamma(1+\phi)][4(1+\phi)-\gamma(2+\phi)]}{\beta\left[8-\gamma^{2}(2+\phi)\right]^{2}}<0$. Thus, when $\gamma=1$, the minimum threshold of $T$ is $\frac{\phi(4-\gamma)^{2}-4 \gamma(2-\gamma)}{8 \beta\left[8-\gamma^{2}(2+\phi)\right]}=\frac{9 \phi-4}{8 \beta(6-\phi)}$. Hence, if $0<T<\frac{9 \phi-4}{8 \beta(6-\phi)}$, then $\pi_{M}^{V I}>\pi_{M}^{S}$ holds for any $\gamma \in[0,1]$.

\section{Appendix E.}

\section{E.1. Proof of Lemma 5.5}

Comparing the retailer $R_{1}$ 's profit under trade credit as in Proposition 4.2 and that under vertical merger as in Proposition 4.5, we have if $\phi=1$, then $\pi_{R_{1}}^{T C}>\left.\pi_{R_{1}}^{V I}\right|_{\phi=1}=0$. If $\phi=0$, due to $q_{R_{1}}^{T C^{*}}<\left.q_{R_{1}}^{V I^{*}}\right|_{\phi=0}$, and then $\pi_{R_{1}}^{T C}<\pi_{R_{1}}^{V I}$. Corollary 4.6 shows that $\pi_{R_{1}}^{V I}$ decreases with $\phi$. We can see that there exists only one root $\phi_{0} \in(0,1)$ such that $\pi_{R_{1}}^{T C}=\pi_{R_{1}}^{V I}$. If $\phi \in\left[0, \phi_{0}\right]$, then $\pi_{R_{1}}^{T C} \leq \pi_{R_{1}}^{V I}$; if $\phi \in\left(\phi_{0}, 1\right]$, then $\pi_{R_{1}}^{T C}>\pi_{R_{1}}^{V I}$.

\section{E.2. Proof of Lemma 5.6}

Comparing the manufacturer's profit under trade credit as in Proposition 4.2 and that under vertical merger as in Proposition 4.5, we have if $\phi=0$, because $-T<0<\left[(\alpha-c)(2-\gamma)-2 c I_{m}\right]^{2}+2 \gamma(2-\gamma)(\alpha-c)^{2}$, and then $\pi_{M}^{T C}>\pi_{M}^{V I}$. If $\phi=1$ and $T<\frac{(\alpha-c)^{2}(2-\gamma)\left(8-4 \gamma+\gamma^{3}\right)}{4 \beta\left(8-3 \gamma^{2}\right)\left(4-\gamma^{2}\right)}+\frac{2\left(8-3 \gamma^{2}\right) c I_{m}\left[(2-\gamma)(\alpha-c)-c I_{m}\right]}{4 \beta\left(8-3 \gamma^{2}\right)\left(4-\gamma^{2}\right)}$, then $\pi_{M}^{T C}<\pi_{M}^{V I}$. Corollary 4.6 shows that $\pi_{M}^{V I}$ increases with $\phi$, and thus there exists only one root $\phi_{1} \in(0,1)$ such that $\pi_{M}^{T C}=\pi_{M}^{V I}$. If $\phi \in\left[0, \phi_{1}\right]$, then $\pi_{M}^{T C} \geq \pi_{M}^{V I}$; while if $\phi \in\left(\phi_{1}, 1\right]$, then $\pi_{M}^{T C}<\pi_{M}^{V I}$.

\section{E.3. Proof of Proposition 5.7}

Combing Lemma 5.5 and Lemma 5.6, Proposition 5.7 can be easily proved.

\section{E.4. Proof of Proposition 5.8}

(1) Let $\Gamma_{1}=\pi_{R_{1}}^{T C}-\pi_{R_{1}}^{V I}$. From Lemma 5.5, $\phi_{0}$ is the root such that $\Gamma_{1}=0$. Taking the derivation of $\gamma$ in both sides of equation $\Gamma_{1}=0$, we have $\frac{\mathrm{d} \phi_{0}}{\mathrm{~d} \gamma}=-\frac{\partial \Gamma_{1} / \partial \gamma}{\partial \Gamma_{1} / \partial \phi_{0}}=-\left[8-\gamma^{2}(2+\phi)\right]^{3} X(\gamma)$, and thus when $X(\gamma) \geq 0$, $\frac{\mathrm{d} \phi_{0}}{\mathrm{~d} \gamma} \leq 0 ;$ and when $X(\gamma)<0, \frac{\mathrm{d} \phi_{0}}{\mathrm{~d} \gamma}>0$.

(2) Let $\Gamma_{2}=\pi_{M}^{T C}-\pi_{M}^{V I}$. From Lemma 5.6, $\phi_{1}$ is the root such that $\Gamma_{2}=0$. Taking the derivation of $\gamma$ in both sides of equation $\Gamma_{2}=0$, we have $\frac{\mathrm{d} \phi_{1}}{\mathrm{~d} \gamma}=-\frac{\partial \Gamma_{2} / \partial \gamma}{\partial \Gamma_{2} / \partial \phi_{1}}=-\frac{Y(\gamma)}{(\alpha-c)^{2}(2-\gamma)^{4}(2+\gamma)^{2}(4+\gamma)^{2}}$. Hence, when $Y(\gamma) \geq 0$, $\frac{\mathrm{d} \phi_{1}}{\mathrm{~d} \gamma} \leq 0 ;$ and when $Y(\gamma)<0, \frac{\mathrm{d} \phi_{1}}{\mathrm{~d} \gamma}>0$.

\section{Appendix F.}

\section{F.1. Proof of Lemma 5.9}

Comparing the retailer $R_{2}$ 's optimal order quantity under different settings, we have $q_{R_{2}}^{S^{*}}>q_{R_{2}}^{T C^{*}}$ because $(2-\gamma)(\alpha-c)>2 c I_{m}$. From Corollary 4.6, $q_{R_{2}}^{V I^{*}}$ decreases with $\phi$, and thus $q_{R_{2}}^{V I^{*}} \leq\left. q_{R_{2}}^{V I^{*}}\right|_{\phi=0}=\frac{\alpha-c}{2 \beta(2+\gamma)}$, which indicates $q_{R_{2}}^{T C^{*}}>q_{R_{2}}^{V I^{*}}$. Thus, we get $q_{R_{2}}^{S^{*}}>q_{R_{2}}^{T C^{*}}>q_{R_{2}}^{V I^{*}}$.

\section{F.2. Proof of Proposition 5.10}

Combining Lemma 5.9, Proposition 4.1, Proposition 4.2, and Proposition 4.5, it is straightforward to derive that $\pi_{R_{2}}^{S}>\pi_{R_{2}}^{T C}>\pi_{R_{2}}^{V I}$. 
Acknowledgements. This research is supported by the Natural Science Foundation of China (Nos. 71502084, 71601098), The Ministry of Education of Humanities and Social Science project (No. 20YJA630086), 2019 Qinglan Project of Jiangsu Province in China, Foundation of Audit Information Engineering and Technology Collaborative Innovation Center in Nanjing Audit University (No. 18CICA05) and Priority Academic Program Development of Jiangsu Higher Eduction Institutions.

\section{REFERENCES}

[1] A. Arya and B. Mittendorf, The changing face of distribution channels: partial forward integration and strategic investments. Prod. Oper. Manage. 22 (2013) 1077-1088.

[2] V. Babich, G. Aydin, P.Y. Brunet, J. Keppo and R. Saigal, Risk, financing and the optimal number of manufacturer. Working paper, Georgetown University, USA (2007).

[3] J.N. Barrot, Trade credit and industry dynamics: Evidence from trucking firms. J. Finance 71 (2016) $1975-2016$.

[4] J. Bian, K.K. Lai, Z. Hua, X. Zhao and G. Zhou, Bertrand vs. Cournot competition in distribution channels with upstream collusion. Int. J. Prod. Econ. 204 (2018) 278-289.

[5] M.J. Brennan, V. Miksimovic and J. Zechner, Vendor financing. J. Finance 43 (1988) 1127-1141.

[6] Business State, Revelation on the change of distribution channel (2012). Available at: http://www.cyzone.cn/a/20100527/ 152574.html (Accessed on May 27, 2010).

[7] J.A. Buzacott and R.Q. Zhang, Inventory management with asset based financing. Manage. Sci. 50 (2004) 1274-1292.

[8] G.P. Cachon and M.A. Lariviere, Supply chain coordination with revenue-sharing contracts: Strengths and limits. Manage. Sci. 51 (2005) 30-44.

[9] S. Carb-Valverde, F. Rodriguez-Fernandez and G.F. Udell, Bank market power and sme financing contraints. Rev. Finance 13 (2009) 309-340.

[10] P. Chen, H. Xu and X. Zou, The effects and incentive of vertical mergers: An analysis from the view of om. Eur. J. Oper. Res. 263 (2017) 158-172.

[11] X. Chen, A model of trade credit in a capital-constrained distribution channel. Int. J. Prod. Econ. 159 (2015) $347-357$.

[12] X. Chen and A. Wang, Trade credit contract with limited liability in the supply chain with budget constraints. Ann. Oper. Res. 196 (2012) 153-165.

[13] W.K. Chiang, D. Chhajed and J.D. Hess, Direct marketing, indirect profits: A strategic analysis of dual channel supply chain design. Manage. Sci. 49 (2003) 1-20.

[14] J. Chod, E. Lyandres and S.A. Yang, Trade credit and supplier competition. Working Paper, London Business School (2016). Available at SSRN: http://ssrn.com/abstract=2849641.

[15] B. Dan, G. Xu and C. Liu, Pricing policies in a dual-channel supply chain with retail services. Int. J. Prod. Econ. 139 (2012) 312-320.

[16] G.W. Emery, A pure financial explanation for trade credit. JFQA 19 (1984) 271-285.

[17] I. Erel, Y. Jang and M. Weisbach, Do acquisitions relieve target firms' financial constraints? J. Finance 70 (2015) $289-328$.

[18] D. Fabbri and L. Klapper, Bargaining power and trade credit. J. Corp. Finance 41 (2016) 66-80.

[19] Y. Fang and B. Shou, Managing supply uncertainty under supply chain Cournot competition. Eur. J. Oper. Res. 243 (2015) 156-176.

[20] R. Fisman and I. Love, Trade credit, financial intermediary development, and industry growth. J. Finance 58 (2003) 353-374.

[21] C.H. Glock and T. Kim, The effect of forward integration on a single-vendor-multi-retailer supply chain under retailer competition. Int. J. Prod. Econ. 164 (2015) 179-192.

[22] D. Gupta and L. Wang, A stochastic inventory model with trade credit. Manufact. Serv. Oper. Manage. 11 (2009) 4-18.

[23] Haier Official Website, The introduction of haier (2016). Available at: http://haier.gitom.com/gywn.htm (Accessed on January $5,2016)$.

[24] M. Hertzel and R.L. Smith, Market discounts and shareholder gains for placing equity privately. J. Finance 48 (1993) $459-485$.

[25] Z. Hua, Y. Sun and X. Xu, Operational causes of bankruptcy propagation in supply chain. Decis. Support Syst. 51 (2011) 671-681.

[26] Huaxia Jingwei, Haier's financing for sme enterprises (2016). Available at: http://www.huaxia.com/tslj/rdqy/xb/2016/04/ 4806320.html (Accessed on April 18, 2016).

[27] C.A. Ingene and M.E. Parry, Channel cooperation when retailers compete. Market. Sci. 14 (1995) 360-377.

[28] International Business, News on luxottica acquires salmoiraghi \& viganò (2016). Available at: http://www.ebrun.com/ 20161201/204576. shtml (Accessed on December 1, 2016).

[29] S. Karray and S.H. Amin, Cooperative advertising in a supply chain with retail competition. Int. J. Prod. Res. 53 (2015) 88-105.

[30] S.H. Khatami, M.T. Marchica, and R. Mura, Corporate acquisitions and financial constraints. Int. Rev. Financial Anal. 40 (2015) 107-121.

[31] P. Kouvelis and W. Zhao, Financing the newsvendor: Manufacturer vs. bank, and the structurer of optimal trade credit contracts. Oper. Res. 60 (2012) 566-580.

[32] Y.W. Lee and J.D. Stowe, Product risk, asymmetric information, and trade credit. JFQA 28 (1993) $285-300$. 
[33] W. Li and J. Chen, Backward integration strategy in a retailer stackelberg supply chain. Omega 75 (2018) 118-130.

[34] H. Liu, S. Sun, M. Lei, H. Deng, and G. K. Leong, The impact of retailers' alliance on manufacturer's profit in a dual-channel structure. Int. J. Prod. Res. 55 (2017) 6592-6607.

[35] K. Matsui, Asymmetric product distribution between symmetric manufacturers using dual-channel supply chains. Eur. J. Oper. Res. 248 (2016) 646-657.

[36] K.S. Moorthy, Product and price competition in a duopoly. Market. Sci. 7 (1988) 141-168.

[37] M.A. Petersen and R.G. Rajan, Trade credit: Theories and evidence. Rev. Financial Stud. 10 (1997) 661-691.

[38] H. Peura, S.A. Yang and G. Lai, Trade credit in competition: A horizontal benefit. Manuf. Serv. Oper. Manage. 19 (2017) $263-289$.

[39] T.J. Richards and M.R. Manfredo, Cooperative mergers and acquisitions: the role of capital constraints. J. Agri. Res. Econ. 28 (2003) 152-168.

[40] D. Seifert, R.W. Seifert and O.H.D. Isaksson, A test of inventory models with permissible delay in payment. Int. J. Prod. Res. 55 (2017) 1117-1128.

[41] D. Seifert, R.W. Seifert and M. Protopappa-Sieke, A review of trade credit literature: Opportunities for research in operations. Eur. J. Oper. Res. 231 (2013) 245-256.

[42] Y.C. Tsao, T.H. Chen and Q.H. Zhang, Effects of maintenance policy on an imperfect production system under trade credit. Int. J. Prod. Res. 51 (2013) 1549-1562.

[43] A.A. Tsay and N. Agrawal, Channel dynamics under price and service competition. Manuf. Serv. Opera. Manage. 2, $372-391$.

[44] Venture News, News on coty acquires $60 \%$ stock of younique (2017). Available at: http://36kr.com/p/5061714.html (Accessed on January 11, 2017).

[45] X. Vives, Duopoly information equilibrium: Cournot and bertrand. J. Econ. Theory 34 (1984) 71-94.

[46] C.H. Wu, C.W. Chen and C.C. Hsieh, Competition pricing decisions in a two-echelon supply chain with horizontal and vertical competition. Int. J. Prod. Econ. 135 (2012) 265-274.

[47] C.H. Wu, N.C. Petruzzi, and D. Chhajed, Vertical integration with price-setting competitive newsvendors. Deci. Sci. 38 (2007) $581-610$.

[48] G. Xu, B. Dan, X. Zhang and C. Liu, Coordinating a dual-channel supply chain with risk-averse under a two-way revenue sharing contract. Int. J. Prod. Econ. 147(Part A) (2014) 171-179.

[49] H. Yang, W. Zhou and L. Shao, Equilibrium evolution in a two-echelon supply chain with financially constrained retailers: The impact of equity financing. Int. J. Prod. Econ. 185 (2017) 139-149.

[50] S.A. Yang and J.R. Birge, Trade credit, risk sharing, and inventory financing portfolios. Manage. Sci. 64 (2018) 3469-3970.

[51] Y. Yu, X. Han, J. Liu and Q. Cheng, Supply chain equilibrium among companies with offline and online selling channels. Int. J. Prod. Res. 55 (2015) 6672-6688.

[52] H. Zhang, Vertical information exchange in a supply chain with duopoly retailers. Prod. Oper. Manage. 11 (2002) 531-546.

[53] Q.H. Zhang, M. Dong, J. Luo and A. Segerstedt, Supply chain coordination with trade credit and quantity discount incorporating default risk. Int. J. Prod. Econ. 153 (2014) 352-360.

[54] Zhengzhou Evening News, Direct store: Home appliances change channel mode (2012). Available at: http://news.ifeng.com/ gundong/detail_2012_01/20/12085086_0.shtml (Accessed on January 20, 2012). 